\title{
Independent Associations of Maternal Education and Household Wealth with Malaria Risk in Children
}

\author{
José G. Siri ${ }^{1}$
}

ABSTRACT. Despite evidence that they play similar but independent roles, maternal education and household wealth are usually conflated in studies of the effects of socioeconomic status (SES) on malaria risk. Demographic and Health Survey and Malaria Indicator Survey data from nine countries in sub-Saharan Africa were used to explore the relationship of malaria parasitemia in children with SES factors at individual and cluster scales, controlling for urban/rural residence and other important covariates. In multilevel logistic regression modeling, completion of six years of maternal schooling was associated with significantly lower odds of infection in children $(\mathrm{OR}=0.73)$, as was a household wealth index at the 40th percentile compared to the lowest percentile $(\mathrm{OR}=0.48)$. These relationships were nonlinear, with significant quadratic terms for both education and wealth. Cluster-level wealth index was also associated with a reduction in risk $(\mathrm{OR}=0.984$ for a one percentile increase in mean wealth index $)$, as was urban residence $(\mathrm{OR}=0.59)$. Among other covariates, increasing child's age and household size category were positively correlated with infection, and sleeping under an insecticidetreated bednet the previous night $(\mathrm{OR}=0.80)$ was associated with a moderate reduction in risk. Considerable variation in parameter estimates was observed among country-specific models. Future work should clearly distinguish between maternal education and household resources in assessing malaria risk, and malaria prevention and control efforts should be aware of the potential benefits of supporting the development of human capital.

Key Words: Demographic and Health Survey; DHS; malaria; Malaria Indicator Survey; maternal education; MIS; multilevel modeling; socioeconomic factors

\section{INTRODUCTION}

A priori expectations and empirical evidence suggest that maternal education affects child health independently of household resources. Yet most studies of the influence of socioeconomic status (SES) variables on health-whether assessing broad indicators like mortality or disease-specific outcomes - equate the effects of wealth and education on risk, thus blurring the distinction between them. Making this distinction is of critical importance in designing effective and costefficient health and development policy for resource-poor nations, and-less well appreciated-it is essential for accurately forecasting the long-run evolution of the burden of disease.

This study examines the association of SES variables with confirmed malaria parasitemia, using data from Malaria Indicator Surveys (MIS) and traditional Demographic and Health Surveys (DHS). The addition of parasitological information to the suite of data collected by DHS offers significant opportunities for improving understanding of how SES relates to malaria risk. This study focuses on the independent associations of household wealth and maternal schooling with malaria in children, in the context of urban versus rural residence. Among these factors, relationships among poverty, urban residence, and malaria risk have been analyzed more often than associations with education. Moreover, the link whereby malaria affects school attendance and educational attainment has been examined in greater depth than the complementary relationship emphasized here-i.e., the effect of maternal education on malaria risk. This study thus provides novel insight in an important area.

Since the turn of the millennium, and increasingly since the call to action by the Bill and Melinda Gates Foundation (2007), a concerted global effort against malaria has achieved major successes, supported by increased funding and ever more sophisticated understandings of the dynamics and operational challenges of malaria control. The scale-up of prevention activities has averted more than 0.8 million deaths in children since 2000 (Eisele et al. 2012). These triumphs have led to loftier goals; e.g., the prevention of all malaria deaths by 2015, progressive regional elimination, and eventually, global eradication (WHO 2011). Yet, while elimination and eradication have emerged firmly back into the global scientific and policy discourse (Feachem and Sabot 2008, Tanner and De Savigny 2008, Malaria Elimination Group 2009, Mendis et al. 2009, Das and Horton 2010, Marsh 2010, Moonen et al. 2010, D'Souza and Newman 2012, Pindolia et al. 2012), technical feasibility studies conclude that we are unlikely to eliminate malaria in hightransmission areas with current capabilities (WHO 2008). Without sustained or increased efforts and funding, regional and global coordination, and an array of novel control tools, malaria is likely to remain viable in areas with high intrinsic transmission rates, particularly in sub-Saharan Africa. In fact, despite recent advances, malaria remains among the most important communicable diseases globally, having caused two-thirds of a million deaths and well over 200 million acute infections in 2010, mostly $(80-90 \%)$ in sub-Saharan Africa (WHO 2011). International funding for malaria control appears to have peaked in 2010 at $\sim$ US $\$ 2$ billion of the estimated US\$5-6 billion per annum needed for elimination (WHO 2011); despite progress, current funding is inadequate for comprehensive malaria control at a global scale (Snow et al. 2010). The recent global financial crisis and competing demands on international financial aid make it doubtful that needed investments will occur or be sustained over the long term. The history of malaria control, of course, is one of significant achievements followed by disease resurgence in areas that lack necessary elements of integrated public health 
infrastructure when economic and financial crises or waning political will have contributed to large-scale reductions in funding for prevention and control (Nájera et al. 2011, Cohen et al. 2012).

It is critical to find and make efficient use of all effective routes for malaria prevention and containment. Malaria control "tool boxes" typically include interventions that directly affect the dynamics of malaria transmission and progression: case management, larval control, insecticide residual spraying, insecticide-treated bednets (ITNs), intermittent preventive treatment in pregnant women, and chemoprophylaxis in travelers or other at-risk groups (Morel et al. 2005). Other interventions, including vaccines (Schwartz et al. 2012) and vector sterilization (Townson 2009), which are on the horizon but not yet available for wide-scale public health action, also directly affect transmission. In contrast, where SES factors influence risk, they generally act indirectly through their effects on other proximal determinants of risk. Moreover, efforts to, say, improve education or decrease poverty are not malaria-specific, may require a much broader set of investments than traditional interventions, and often generate more controversy as well. Yet, to the extent that these factors determine risk, the potential of such efforts to constitute important formal components of larger scale policy for malaria control should be considered in greater detail.

There is no question that SES factors are correlated with malaria risk. Higher standards of living, for example, were instrumental in the large-scale reductions in malaria in North America and Europe during the late 19th and early 20th centuries (Humphreys 2001). Today, the poorest populations worldwide bear a disproportionate number of malaria cases and deaths (Barat et al. 2004). However, causality in the relationship between SES factors and malaria is likely bidirectional. For example, it is probable that malaria causes poverty and vice versa, in reinforcing feedback cycles at the individual, community, and potentially national or regional scales (Somi et al. 2007, Teklehaimanot and Mejia 2008).

On the one hand, then, researchers have examined how malaria affects SES factors. At the national level, a widely cited set of studies has associated malaria endemicity with substantially slower economic growth and decreased per capita GDP (Gallup and Sachs 2001, Sachs and Malaney 2002), although the causality of these relationships has been questioned given the inadequacy of data, complexity of interrelationships among social and economic factors and health, and difficulty of extrapolating microlevel results to the macro level (Packard 2009). At the household and individual levels, malaria imposes significant burdens, both direct, in terms of the costs of prevention and treatment, and indirect, in the form of lost wages. Such impacts are, of course, felt more keenly among the poor, for whom they constitute a much greater fraction of available resources (Chima et al. 2003, Teklehaimanot and Mejia 2008). Malaria also affects human capital formation by increasing school absenteeism in areas of high transmission and decreasing school performance subsequent to malaria episodes (e.g., Vitor-Silva et al. 2009). Severe malaria syndromes, including severe anemia and cerebral malaria, can have physiological and neurological sequelae which result in decreased cognitive and reasoning ability, with long-term consequences for intellectual development and productivity (Chima et al. 2003).
This study is more interested in the complementary link; i.e., how SES factors affect malaria risk. Worrall et al. (2005), in a review of a range of microlevel studies, found strong associations between various SES proxies and uptake of malaria prevention and treatment but inconclusive evidence for a causal effect of SES on incidence. Filmer (2005), using DHS data for 22 countries, found a general pattern of lower fever in children with higher household SES (measured by a wealth-based asset index), but results were significant in only three countries; the study did not find a significant association between fever in children and mother's years of schooling. Moreover, the use of fever as a proxy for malaria infection is inexact and can result in considerable misclassification, which thus overestimates the impact of uncomplicated episodes while underestimating the consequences of severe disease (Chima et al. 2003). Since 2010, WHO guidelines have specified that all suspected cases of malaria should be confirmed via microscopy or rapid diagnostic tests (WHO 2010). Some studies have associated SES factors with severe disease; e.g., in Western Kenya, lower household wealth percentile was associated with higher odds of clinically confirmed malarial anemia (Siri et al. 2010). Poverty is clearly associated with other factors linked to malaria risk. For example, the poor are less likely to be able to pay for ITNs or other prevention or to seek or obtain adequate treatment. The poor are also more likely to live in substandard housing, which allows vectors access to sleeping individuals, and thus strongly increases risk (Lindsay and Snow 1988).

Evidence is inconclusive as to the specific effect of adult education on malaria in children. No association was found between educational level of parents or guardians and severe or mild malaria in children in the Gambia (Koram et al. 1995a, b), or between maternal educational attainment and malaria severity or time to reinfection in Gabon (Luckner et al. 1998), febrile episodes in Benin (Rashed et al. 2000), or malaria infection in Equatorial Guinea (Custodio et al. 2009). In contrast, Villamor et al. (2003) found that maternal schooling strongly reduced baseline parasitemia when other indicators of socioeconomic status were controlled for; where mothers had no education, children had $43 \%$ higher adjusted prevalence. In Mali, maternal completion of primary school halved the risk of severe malaria in their children, even though most educated mothers $(84.2 \%)$ did not have adequate knowledge about malaria (Safeukui-Noubissi et al. 2004). In Western Kenya, caretaker's level of education was correlated with child parasitemia and malarial anemia in univariate analysis but not when controlling for other factors (Ong'echa et al. 2006). In Brazzaville, Congo, the odds of presenting with cerebral malaria were $90 \%$ higher among children whose mothers had less than a primary school education (Carme et al. 1994). Noor et al. (2006) found that mother's educational attainment was strongly predictive of retail sector ITN use in Kenya; this is one of several studies that have linked schooling with preventive behavior or treatment seeking (see Worrall et al. 2005).

Just a few studies have attempted to evaluate both causal pathways simultaneously. Somi et al. (2007) and de Castro and Fisher (2012) used instrumental variable approaches to account for endogeneity in the relationship between SES and malaria in Tanzania - the former used data from 52 villages within the framework of two major demographic surveillance sites, the 
latter from a 2007-2008 special country-wide DHS survey. Somi et al. (2007) found that household SES was negatively and significantly associated with malaria parasitemia, and that parasitemia, in turn, had a significant negative effect on the wealth-based asset index used to measure wealth. That study used education level of the household head as an instrument because it showed no association with parasitemia; education of the mother was not among the variables considered for analysis. In contrast, de Castro and Fisher (2012) found that malaria illness among young children contributed to lower household wealth, but lower household wealth did not contribute to a higher incidence of malaria. Having either a father or mother with secondary or higher education did not influence malaria risk.

Education of the mother, father, or household head is often included as an ancillary variable in studies of malaria risk factors, and the discussion here is not comprehensive. Yet, even a cursory review underscores that education is rarely the primary focus of research. In fact, education (most often measured in terms of educational attainment but more broadly encompassing the accumulation of knowledge, skills, networks, and intangible assets like trust) is often conflated with economics (usually, wealth measured by an asset index but more generally comprising resources available to address household needs). For example, education of the household head may be included in asset-based wealth indices (e.g., Schellenberg et al. 2003), which renders it inaccessible to analysis as an independent risk factor. Implicitly or explicitly, the focus of many studies is on poverty, even where information on education is collected.

In different contexts, it has been shown that the distinction between such indicators is critical in estimating impacts of SES factors on health, that they act along distinct causal pathways, and that equating them can obscure true relationships (Geyer et al. 2006). Thus, DHS data have been used to show that the effect of mothers' educational attainment on child mortality is often of greater significance than the effect of household wealth, when controlling for potential confounders (Fuchs et al. 2010, Pamuk et al. 2011), or that economic development level, household wealth, and maternal educational attainment have strong independent associations with child health, as indicated by weight and height for age (Boyle et al. 2006). Similarly, de Souza et al. (1999) used census and health systems data in Brazil to show that female illiteracy was associated with higher infant mortality. A broad systematic review of global child mortality found that between 1970 and 2009, increased educational attainment in women accounted for more than half of an estimated 8.2 million averted deaths in children younger than 5 years (Gakidou et al. 2010). Various studies have also found that maternal schooling affects infant mortality when controlling for malaria endemicity (Gemperli et al. 2004, Kazembe et al. 2007).

There are a number of mechanisms by which parental educational attainment is likely to affect health (e.g., Fuchs et al. 2010). Schooling may directly provide health-specific information or increase the ability of individuals to acquire and understand such information; it may increase their familiarity with formal institutions, and thus lead to greater trust in and use of health facilities or preventive measures; it is likely to increase the autonomy and empowerment of women; and it has positive effects on income and household resources. Even where such benefits do not accrue, school attendees may develop social networks whose example or intervention can contribute to healthy behaviors. Community-level education may contribute to child health over and above the individual effect of maternal educational attainment through increases in the general empowerment of women, pooled community knowledge, or the imitation of healthy behaviors by less-educated individuals (Pamuk et al. 2011). Offsetting these factors to a certain degree, parental education may actually reduce health in some cases. For example, better educated mothers may be less likely to breast-feed than their less educated counterparts. Better educated parents also face a higher opportunity cost in terms of foregone productivity when choosing to devote time to child-rearing and household maintenance.

This study measures the independent associations of mothers' educational attainment and household resources with malaria using DHS/MIS data. A series of studies has recently used MIS data to map risk of malaria parasitemia in various countries (Gosoniu et al. 2010, 2012, Giardina et al. 2012), but while these studies have evaluated associations with SES (as measured by the DHS wealth index) and, generally, with urban residence, they have not incorporated education in modeling malaria prevalence.

\section{METHODS}

\section{Data sources and variables}

Since 1985, the Measure DHS project has collected data on demography and health through standardized national surveys (MeasureDHS 2013). The regular DHS survey includes a wealth of information on health behaviors, specific health issues such as anemia, malnutrition, malaria, and HIV, and a range of individual and household-level socio-demographic factors (Rutstein and Rojas 2006). DHS surveys in malaria-endemic areas have long collected self-reported information about fever and malaria-preventive behaviors but more recently have begun to include biomarker data; i.e., laboratory confirmed malaria parasitemia and anemia in children and pregnant women. Since 2006, the new MIS survey, developed in conjunction with Roll Back Malaria and focused specifically on malaria-relevant information, has been administered in endemic areas, primarily in sub-Saharan Africa. Thirty-two MIS surveys and more than 300 DHS surveys have been conducted in more than 90 countries (MeasureDHS 2013).

DHS/MIS surveys are designed to collect data that are representative of the situation of a particular country (ICF International 2012). They use a hierarchical sample design: first, a sample of clusters, usually census enumeration areas, is selected; second, all households within these clusters are enumerated and a second-stage sample of households is systematically identified for interview. Clusters may be chosen so as to achieve sufficient sample size within regional or urban/rural strata; sampling weights, corrected for stratum-specific nonresponse, allow for accurate estimation of population parameters. For surveys that deal with malaria biomarkers, blood specimens are collected for a subset of the overall sample and are tested for anemia and parasitemia. At the national scale, surveys are managed by national implementing agencies in collaboration with Measure DHS. Interviewers receive extensive training and interact with local authorities in identifying selected households and 
Table 1. Household-level Demographic and Health Surveys (DHS)/Malaria Indicator Surveys (MIS) used in analyses, and sample size (AIS: AIDS Indicator Survey).

\begin{tabular}{|c|c|c|c|c|c|c|}
\hline Country & Year & $\begin{array}{l}\text { Survey } \\
\text { type }\end{array}$ & $\begin{array}{c}\text { Number of sampled } \\
\text { clusters } \\
\left(N^{\text {clust }}\right)\end{array}$ & $\begin{array}{c}\text { Number of sampled } \\
\text { households } \\
\left(N^{\text {house }}\right)\end{array}$ & $\begin{array}{c}\text { Number of sampled } \\
\text { mothers } \\
\left(N^{\text {mother }}\right)\end{array}$ & $\begin{array}{l}\text { Number of sampled } \\
\text { children } \\
(N)\end{array}$ \\
\hline Angola & 2011 & MIS & 240 & 1840 & 1981 & 2900 \\
\hline Liberia & 2011 & MIS & 150 & 1721 & 1869 & 2436 \\
\hline Uganda & 2009 & MIS & 170 & 2179 & 2254 & 3400 \\
\hline Malawi & 2012 & MIS & 140 & 1472 & 1501 & 1896 \\
\hline Rwanda & 2010 & DHS & 492 & 2801 & 2848 & 3699 \\
\hline Senegal & $2008-9$ & MIS & 320 & 1814 & 2654 & 3562 \\
\hline Tanzania & 2011-12 & AIS/MIS & 916 & 4498 & 4895 & 6634 \\
\hline Nigeria & 2010 & MIS & 240 & 2679 & 3019 & 4353 \\
\hline Madagascar & 2011 & MIS & 268 & 3768 & 3885 & 5257 \\
\hline
\end{tabular}

administering questionnaires. Confidentiality of information is a major concern: DHS surveys are anonymous, and strict efforts are made to prevent the disclosure of respondent identity.

All currently available MIS or DHS surveys that report confirmed malaria parasitemia in children (Table 1) were obtained. Because all of these data sets originate in sub-Saharan Africa (Fig. 1), most infections are due to Plasmodium falciparum, the most lethal malaria parasite (Cibulskis et al. 2011). From these sources, a global data set $(N=34,137)$ was created, consisting of records for all children under 5 years of age with a valid malaria parasitemia test and valid information on maternal education and household wealth. All data processing and statistical analysis was performed in SAS 9.2 (SAS Institute Inc., Cary, NC). Fig. 1 was produced using R ( R Core Team 2013) in the RStudio Integrated Development Environment (RStudio 2013).

Fig. 1. Map of Demographic and Health Surveys/Malaria Indicator Surveys included, and other surveys with information on malaria parasitemia.

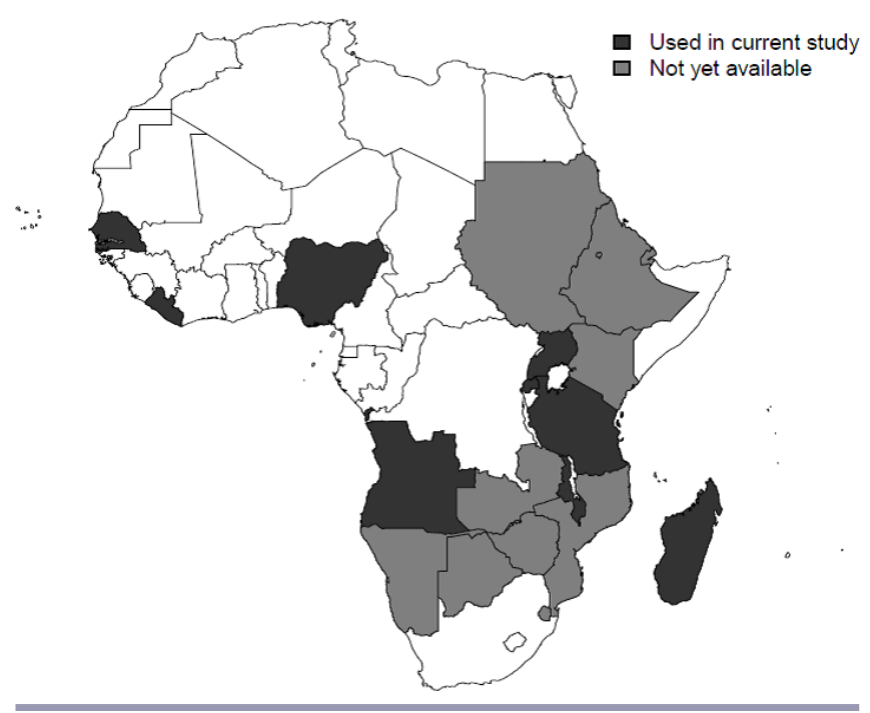

DHS/MIS data contain a multitude of indicators that are potentially related to malaria occurrence, from which a conservative set of explanatory variables (Table 2) was selected. In particular, the main variables of interest-i.e., household wealth, maternal educational attainment, and urban residencewere included a priori. Cluster-level education and wealth were also added to assess the influence of community-level factors. To account for clustering at various scales and the hierarchical nature of data collection, country and identifying numbers for sample cluster and household were retained. Several other variables that have been shown to strongly and consistently affect malaria incidence were added as covariates in order to avoid omittedvariable bias due to confounding. Confounding may arise where a variable is both a cause of the dependent variable and is associated with one or more independent variables. These include child's age - one of the best predictors of parasitemia - and use of ITNs and housing quality, both of which are reliably associated with reduced risk. Household size was also included because it relates strongly to wealth and to malaria in some contexts. For example, it may influence the likelihood of being bitten by a mosquito or the likelihood that nearby vectors have acquired infection. Similarly, sex of the household head was included as potentially indicative of priorities about how household resources are used. Where several available variables were related or assumed to have similar effects, a judgment was made as to which was most relevant to the analysis in order to avoid multicollinearity and limit the number of independent variables. For example, whether the child slept under an ITN the previous night was adopted as more directly reflective of infection risk than whether the household owned bednets or ITNs, or than the number of bednets or ITNs or the time since treatment of ITNs. Moreover, only variables available from all country data sets were considered eligible for inclusion, which eliminated several potentially relevant variables from consideration (e.g., recent insecticide residual spraying, education of the household head, knowledge of malaria transmission and prevention). Some potentially relevant variables were beyond the scope of this study (e.g., geographic locations of interviewed households and associated environmental or epidemiological variables). 
Table 2. Contextual, household, and individual variables retained.

\section{Variable}

Country

Cluster

Household

Whether household is urban

Household size (i.e., number of de jure members)

Quality of housing (i.e., whether windows and ceilings are made of

finished materials)

Sex of household head

Mother's age

Child's age

Whether child slept under insecticide-treated bednet during previous night

Mother's educational attainment (highest grade completed)

Household asset-based wealth index constructed from:

Car ownership

Motorcycle ownership

Bicycle ownership

Refrigerator ownership

TV ownership

Radio ownership

Mobile phone ownership

Whether residence has electricity

Whether residence has an improved source of drinking water

Whether residence has a flush toilet

Number of dwelling rooms in residence

Whether floor of residence is made of finished materials

Cluster-level mean of mother's educational attainment

Cluster-level mean of household asset-based wealth index

$\dagger$ According to the WHO/UNICEF Joint Monitoring Programme for Water Supply and Sanitation definition for improved drinking water sources: http://www.wssinfo.org/definitions-methods/watsancategories/

Where applicable, the accuracy of country-level distributions for explanatory variables and for malaria parasitemia was assessed through comparison with published summary data for DHS/MIS samples (Ndiaye and Ayad 2009, Uganda Bureau of Statistics and ICF Macro 2010, Cosep Consultoria, Consaúde e ICF Macro 2011, National Institute of Statistics of Rwanda [Rwanda], Ministry of Health [Rwanda], and ICF International 2012, National Malaria Control Program [Liberia], Ministry of Health and Social Welfare, Liberia Institute of Statistics and GeoInformation Services, and ICF International 2012, National Malaria Control Programme [Malawi] and ICF International 2012, National Population Commission [Nigeria], National Malaria Control Programme [Nigeria], and ICF International 2012, Tanzania Commission for AIDS, Zanzibar AIDS Commission, National Bureau of Statistics, Office of the Chief Government Statistician, and ICF International 2013).

Because the standard DHS wealth index often incorporates variables that are likely to independently affect malaria risk (e.g., bednet ownership, quality of housing) (Rutstein and Johnson 2004), a new asset-based wealth index was constructed for each country, following standard methodology (Filmer and Pritchett 2001). Briefly, principal components analysis (PCA) of household-related variables (Table 2) was used to characterize the underlying distribution of household wealth. PCA identifies linear weighted combinations of variables that explain the largest possible amount of variation in the data; these components capture common information in the original variables, and can be substituted for them to reduce the number of variables under consideration (Vyas and Kumaranayake 2006). When performed using household assets, the first principal component is commonly assumed to represent household wealth, which is difficult to measure directly, and can be indexed in quantiles for this purpose. The internal validity of this index was assessed by examining the proportion of households in each wealth quintile with the corresponding assets (Appendix Table A1.1).

\section{Statistical analysis}

Malaria parasitemia was characterized by wealth quintile and standard educational attainment categories (i.e., none, primary, secondary, or higher), along with urban residence and other covariates, for each country (Table 3 ). Other continuous variables were also categorized to allow for simple stratified analysis. Bivariate associations between parasitemia and other variables were assessed using Pearson's Chi-square test (Pearson 1900).

As a preliminary step in evaluating the independent associations of maternal education and wealth with malaria, these variables were dichotomized - splitting wealth at the median and education at any/no schooling - and parasitemia was compared among the four cross-tabulated groups, overall and stratified by urban residence, for each country (Table 4 ). This analysis was extended with simple country-level logistic regression models (Aldrich and Nelson 1984), including categorized education and wealth and urban residence (Table 5). Fig. 2 represents these results graphically by illustrating individual country and mean odds ratios for malaria parasitemia in children for urban residence, maternal education, and household wealth.

Fig. 2. Country-specific and mean odds ratios for malaria parasitemia in children for urban residence, maternal education category, and wealth quintile from country-specific reduced (IA) hierarchical logistic regression models.

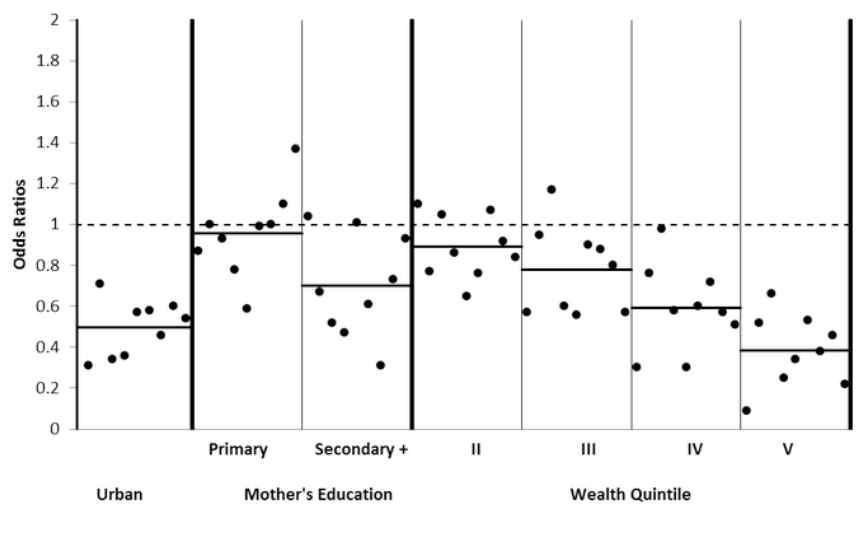

Multivariate logistic regression models were fit to the global data set to estimate the magnitude of association between risk factors and malaria parasitemia. In particular, because data from DHS/ MIS violate the assumption of independence within households, sample clusters, and countries (i.e., because malaria is an infectious condition and because individuals in the same cluster/ country are subject to similar contextual risk factors), hierarchical 
Table 3. Malaria parasitemia by contextual, household, and individual risk factors: parasite rate ( $\%$ of population).

\begin{tabular}{|c|c|c|c|c|c|c|c|c|c|}
\hline & $\begin{array}{c}\text { Angola } \\
\left(n^{\text {pop }}=2900 ;\right. \\
\left.n^{\text {clust }}=240\right)\end{array}$ & $\begin{array}{c}\text { Liberia } \\
\left(n^{\text {pop }}=2436 ;\right. \\
\left.n^{\text {clust }}=150\right)\end{array}$ & $\begin{array}{c}\text { Uganda } \\
\left(n^{\text {pop }}=3400 ;\right. \\
\left.n^{\text {clust }}=170\right)\end{array}$ & $\begin{array}{c}\text { Malawi } \\
\left(n^{\text {pop }}=1896 ;\right. \\
\left.n^{\text {clust }}=140\right)\end{array}$ & $\begin{array}{c}\text { Rwanda } \\
\left(n^{\text {pop }}=3699 ;\right. \\
\left.n^{\text {clust }}=492\right)\end{array}$ & $\begin{array}{c}\text { Senegal } \\
\left(n^{\text {pop }}=3562 ;\right. \\
\left.n^{\text {clust }}=320\right)\end{array}$ & $\begin{array}{c}\text { Tanzania } \\
\left(n^{\text {pop }}=6634 ;\right. \\
\left.n^{\text {clust }}=916\right)\end{array}$ & $\begin{array}{c}\text { Nigeria } \\
\left(n^{\text {pop }}=4353 ;\right. \\
\left.n^{\text {clust }}=240\right)\end{array}$ & $\begin{array}{c}\text { Madagascar } \\
\left(n^{\text {pop }}=5257 ;\right. \\
\left.n^{\text {clust }}=268\right)\end{array}$ \\
\hline $\begin{array}{l}\text { Residence } \\
\text { location }\end{array}$ & $* * *$ & $* * *$ & $* * *$ & $* * *$ & & $* * *$ & $* * *$ & $* * *$ & $* * *$ \\
\hline Rural & $18.3(68.6)$ & $53.9(62.2)$ & $54.0(88.0)$ & $47.0(86.9)$ & $2.5(88.5)$ & $14.5(64.1)$ & $9.9(83.9)$ & $55.2(76.8)$ & $8.8(94.4)$ \\
\hline Urban & $1.7(31.4)$ & $29.7(37.8)$ & $31.8(12.0)$ & $14.4(13.1)$ & $1.1(11.5)$ & $7.2(35.9)$ & $3.3(16.1)$ & $36.8(23.2)$ & $1.9(5.6)$ \\
\hline $\begin{array}{l}\text { Mother's highest } \\
\text { level of } \\
\text { schooling }\end{array}$ & $* * *$ & $* * *$ & $* * *$ & $* * *$ & $*$ & $* * *$ & $* * *$ & $* * *$ & $* * *$ \\
\hline None & $20.3(35.1)$ & $49.9(48.2)$ & $55.7(21.7)$ & $52.9(21.2)$ & $3.9(19.4)$ & $13.3(69.4)$ & $10.2(24.3)$ & $57.9(51.5)$ & $9.5(27.9)$ \\
\hline Primary & $10.2(55.2)$ & $47.7(30.3)$ & $53.7(62.5)$ & $44.1(64.5)$ & $2.0(72.2)$ & $9.0(22.8)$ & $8.9(67.4)$ & $53.7(19.8)$ & $9.3(54.3)$ \\
\hline Secondary+ & $3.2(9.8)$ & $29.2(21.4)$ & $35.6(15.8)$ & $21.8(14.3)$ & $2.1(8.4)$ & $7.5(7.9)$ & $3.5(8.4)$ & $36.4(28.7)$ & $4.1(17.9)$ \\
\hline Wealth quintile & $* * *$ & $* * *$ & $* * *$ & $* * *$ & $* * *$ & $* * *$ & $* * *$ & $* * *$ & $* * *$ \\
\hline I (lowest) & $23.4(20.1)$ & $54.1(19.1)$ & $52.4(18.3)$ & $57.6(23.6)$ & $4.2(23.6)$ & $17.5(14.9)$ & $11.0(21.4)$ & $61.0(21.7)$ & $13.9(22.6)$ \\
\hline II & $23.5(19.9)$ & $50.5(21.7)$ & $54.6(21.0)$ & $49.4(21.7)$ & $2.5(16.2)$ & $14.0(16.8)$ & $11.8(20.7)$ & $59.6(21.7)$ & $10.8(20.9)$ \\
\hline III & $12.1(21.8)$ & $51.5(16.8)$ & $57.2(21.5)$ & $40.9(20.6)$ & $2.1(21.0)$ & $15.3(16.0)$ & $10.1(19.4)$ & $54.0(20.7)$ & $7.4(20.3)$ \\
\hline IV & $4.3(19.9)$ & $40.0(19.7)$ & $52.7(20.3)$ & $37.9(20.0)$ & $1.2(19.8)$ & $8.9(25.8)$ & $7.9(18.9)$ & $42.7(17.7)$ & $5.9(21.0)$ \\
\hline V (highest) & $1.1(18.3)$ & $30.3(22.7)$ & $38.5(19.0)$ & $17.3(14.2)$ & $1.4(19.5)$ & $8.2(26.6)$ & $3.0(19.7)$ & $33.1(18.3)$ & $1.8(15.2)$ \\
\hline $\begin{array}{l}\text { Child's age } \\
\text { (months) }\end{array}$ & $* *$ & $* * *$ & $* * *$ & $* * *$ & & $* *$ & $* * *$ & $* * *$ & $* * *$ \\
\hline $6-11$ & $9.6(13.3)$ & $25.1(11.5)$ & $34.4(21.1)$ & $35.0(9.9)$ & $0.9(11.2)$ & $6.7(10.2)$ & $4.3(12.9)$ & $42.0(12.4)$ & $4.0(12.1)$ \\
\hline $12-23$ & $11.3(23.6)$ & $34.2(26.8)$ & $47.6(20.6)$ & $34.6(25.8)$ & $2.5(20.9)$ & $10.2(23.6)$ & $7.7(25.1)$ & $46.8(21.5)$ & $7.1(19.8)$ \\
\hline $24-35$ & $12.8(22.7)$ & $47.0(20.2)$ & $57.6(20.0)$ & $44.0(21.5)$ & $2.0(23.7)$ & $12.9(21.5)$ & $8.9(21.4)$ & $49.9(20.5)$ & $7.1(21.9)$ \\
\hline $36+$ & $15.4(40.5)$ & $56.0(41.5)$ & $59.3(38.3)$ & $48.8(42.8)$ & $2.8(44.3)$ & $13.4(44.8)$ & $10.9(40.6)$ & $55.7(45.6)$ & $10.7(46.1)$ \\
\hline $\begin{array}{l}\text { Child slept under } \\
\text { insecticide- } \\
\text { treated bednet }\end{array}$ & $* * *$ & & $* *$ & * & $* * *$ & & & & $* *$ \\
\hline No & $14.9(73.2)$ & $45.0(62.5)$ & $53.4(64.8)$ & $45.6(39.8)$ & $3.6(29.4)$ & $11.9(67.2)$ & $7.7(26.5)$ & $51.5(69.1)$ & $6.2(22.8)$ \\
\hline Yes & $8.1(26.8)$ & $44.5(37.5)$ & $47.5(35.2)$ & $40.9(60.2)$ & $1.8(70.7)$ & $11.8(32.8)$ & $9.2(73.5)$ & $49.6(30.9)$ & $9.1(77.2)$ \\
\hline $\begin{array}{l}\text { Finished } \\
\text { windows and } \\
\text { ceilings }\end{array}$ & $* * *$ & $* * *$ & $* * *$ & $* * *$ & $* *$ & $* * *$ & $* * *$ & $* * *$ & $* * *$ \\
\hline No & $17.8(69.0)$ & $52.2(66.2)$ & $54.1(75.2)$ & $50.2(71.4)$ & $3.0(54.0)$ & $16.4(40.7)$ & $11.5(51.9)$ & $57.3(61.2)$ & $9.4(84.4)$ \\
\hline Yes & $2.5(31.0)$ & $30.3(33.8)$ & $42.8(24.8)$ & $24.2(28.6)$ & $1.5(46.0)$ & $8.8(59.3)$ & $5.9(48.1)$ & $40.8(38.8)$ & $3.1(15.6)$ \\
\hline Household size & & & $* *$ & & & & $* * *$ & $* *$ & $*$ \\
\hline $1-4$ & $11.4(25.3)$ & $41.9(27.6)$ & $45.8(26.1)$ & $39.3(37.6)$ & $2.5(36.9)$ & $13.3(3.9)$ & $7.6(21.3)$ & $47.2(19.1)$ & $7.9(28.8)$ \\
\hline $5-6$ & $14.8(37.9)$ & $45.2(33.4)$ & $53.4(33.2)$ & $45.9(39.4)$ & $2.4(35.9)$ & $11.3(11.0)$ & $6.8(30.3)$ & $49.2(29.3)$ & $7.5(34.4)$ \\
\hline $7-8$ & $12.6(22.9)$ & $45.6(21.7)$ & $53.1(25.6)$ & $43.0(18.2)$ & $1.8(20.1)$ & $11.6(12.7)$ & $10.4(22.5)$ & $53.0(21.4)$ & $8.7(21.0)$ \\
\hline $9+$ & $12.2(13.9)$ & $47.6(17.3)$ & $53.1(15.1)$ & $42.3(4.8)$ & $2.7(7.1)$ & $11.9(72.4)$ & $10.9(25.9)$ & $53.5(30.2)$ & $10.9(15.9)$ \\
\hline $\begin{array}{l}\text { Mother's age } \\
\text { (years) }\end{array}$ & & & & & & $* *$ & $*$ & & $*$ \\
\hline$<20$ & $9.1(11.1)$ & $35.5(6.1)$ & $45.6(4.9)$ & $36.0(4.8)$ & $2.7(1.0)$ & $13.2(4.9)$ & $9.9(4.8)$ & $54.2(4.3)$ & $7.9(7.2)$ \\
\hline $20-29$ & $12.9(54.2)$ & $45.9(52.3)$ & $51.1(55.6)$ & $42.2(53.4)$ & $2.4(46.8)$ & $10.1(48.7)$ & $9.0(49.1)$ & $50.1(47.2)$ & $8.5(47.4)$ \\
\hline $30-39$ & $14.6(28.4)$ & $45.9(31.7)$ & $51.0(31.6)$ & $43.2(34.9)$ & $2.1(39.2)$ & $14.2(38.3)$ & $7.8(36.1)$ & $51.2(37.7)$ & $7.5(35.4)$ \\
\hline $40+$ & $14.5(6.4)$ & $41.0(9.9)$ & $57.5(8.0)$ & $49.4(7.0)$ & $2.9(13.0)$ & $10.6(8.2)$ & $10.9(9.9)$ & $52.4(10.7)$ & $11.7(10.1)$ \\
\hline $\begin{array}{l}\text { Sex of household } \\
\text { head }\end{array}$ & $* * *$ & $* *$ & & & & $* * *$ & & & \\
\hline Male & $11.6(81.8)$ & $47.0(70.2)$ & $51.2(78.1)$ & $43.8(78.5)$ & $2.3(78.9)$ & $12.6(87.0)$ & $8.7(83.5)$ & $50.9(92.3)$ & $8.7(83.4)$ \\
\hline Female & $19.6(18.2)$ & $39.5(29.8)$ & $51.7(21.9)$ & $38.8(21.5)$ & $2.5(21.1)$ & $6.8(13.0)$ & $9.4(16.5)$ & $51.0(7.8)$ & $7.2(16.6)$ \\
\hline
\end{tabular}

multilevel models were constructed using the generalized linear mixed modeling procedure in SAS (Kiernan et al. 2012). Such models are appropriate where data have been collected in nested units, as is the case for DHS/MIS surveys. These models account for the hierarchical nature of the data by adjusting for the correlation of observations within higher level groups and allowing observed variance to be apportioned among grouplevel and individual effects.

In particular, sampling cluster and household, which were selected from among larger distributions of possible samples or surveys, were included in the model as nested random effects, 
Table 4. Malaria parasitemia (\%) by any/no maternal education and above/below median wealth, stratified by urban residence.

\begin{tabular}{|c|c|c|c|c|c|c|c|c|c|c|c|c|}
\hline \multirow[b]{2}{*}{$\begin{array}{l}\text { Education / } \\
\text { Wealth }\end{array}$} & \multicolumn{4}{|c|}{ Rural } & \multicolumn{4}{|c|}{ Urban } & \multicolumn{4}{|c|}{ Total } \\
\hline & $\begin{array}{r}\text { Low/ } \\
\text { Low } \\
\end{array}$ & $\begin{array}{l}\text { Low/ } \\
\text { High }\end{array}$ & $\begin{array}{r}\text { High/ } \\
\text { Low }\end{array}$ & $\begin{array}{r}\text { High/ } \\
\text { High }\end{array}$ & $\begin{array}{r}\text { Low/ } \\
\text { Low } \\
\end{array}$ & $\begin{array}{l}\text { Low/ } \\
\text { High }\end{array}$ & $\begin{array}{r}\text { High/ } \\
\text { Low }\end{array}$ & $\begin{array}{c}\text { High/ } \\
\text { High }\end{array}$ & $\begin{array}{l}\text { Low/ } \\
\text { Low }\end{array}$ & $\begin{array}{l}\text { Low/ } \\
\text { High }\end{array}$ & $\begin{array}{r}\text { High/ } \\
\text { Low }\end{array}$ & $\begin{array}{r}\text { High/ } \\
\text { High } \\
\end{array}$ \\
\hline Angola & 23.0 & 12.3 & 20.2 & 8.8 & $0 \dagger$ & 7.0 & $4.9 \dagger$ & 1.1 & 22.9 & 10.6 & 19.4 & 3.8 \\
\hline Liberia & 53.7 & 52.8 & 52.8 & 55.6 & 42.4 & 36.3 & 47.8 & 22.6 & 52.5 & 44.8 & 51.8 & 33.2 \\
\hline Uganda & 54.8 & 65.2 & 53.1 & 52.5 & $34.8 \dagger$ & $28.7 \dagger$ & $61.7 \dagger$ & 27.9 & 54.6 & 59.0 & 53.4 & 47.3 \\
\hline Malawi & 60.9 & 44.8 & 51.0 & 37.8 & $28.3 \dagger$ & $2.6 \dagger$ & 29.9 & 11.8 & 60.1 & 40.4 & 49.8 & 31.7 \\
\hline Rwanda & 4.4 & 3.9 & 2.4 & 1.5 & $0 \dagger$ & $0 \dagger$ & $2.1 \dagger$ & 1.1 & 4.2 & 3.6 & 2.4 & 1.4 \\
\hline Senegal & 17.3 & 9.5 & 14.5 & 9.0 & 4.1 & 9.4 & 6.2 & 5.8 & 15.9 & 9.5 & 12.1 & 6.7 \\
\hline Tanzania & 11.2 & 10.8 & 11.3 & 7.6 & $4.0 \dagger$ & $2.2 \dagger$ & 11.9 & 2.5 & 11.0 & 10.2 & 11.4 & 6.0 \\
\hline Nigeria & 61.5 & 51.6 & 57.6 & 46.4 & 58.6 & 41.7 & 52.4 & 29.2 & 61.2 & 49.9 & 57.0 & 38.8 \\
\hline Madagascar & 12.6 & 6.8 & 12.4 & 5.3 & $16.2 \dagger$ & 0 & $1.9 \dagger$ & 1.9 & 12.6 & 6.6 & 12.3 & 4.9 \\
\hline
\end{tabular}

$\dagger$ Less than 50 observations in cell

while other variables (Table 2), including country, were modeled as fixed effects. Accordingly, the models allowed the intercept to vary randomly at the cluster and household levels. Variance inflation factors (Velleman and Welsch 1981) were examined to test for potential multicollinearity.

First, a minimal (IIA) model was estimated (Table 6), with education and wealth included as continuous variables and dummy variables used for urban residence and survey country. To this were sequentially added cluster-level SES variables (IIB), nonlinear (i.e., polynomial) SES terms (IIC), and other covariates (IID). Both stratified analysis and Box-Tidwell tests suggested nonlinear effects for education and wealth. The Box-Tidwell test adds a continuous variable along with its Box-Tidwell transformation $(\mathrm{x} * \log [\mathrm{x}])$ to the logistic regression model. A significant effect for the transformed variable indicates violation of the assumption of linearity (Box and Tidwell 1962). Thus, quadratic $\left(\mathrm{x}^{2}\right)$ terms and interactions (i.e., education * wealth, education * urban residence, and wealth * urban residence), either of which can result in nonlinear effects, were evaluated. Because initial examination of variance inflation factors when higher order terms were incorporated indicated significant multicollinearity, wealth percentile and years of education were centered around their grand means, and these terms were regenerated; subsequently, no major multicollinearity was observed (i.e., all variance inflation factors were less than 4.0). An incremental approach was adopted, which involved adding quadratic terms, assessing significance and model fit, and then assessing any added effect of interactions. In fact, no interactions were found to have significant additional effects, and they were left out of the final model.

\section{RESULTS}

\section{Exploratory data analysis}

Table 3 shows bivariate associations between malaria parasitemia in children and explanatory variables. Of these, links with wealth, maternal schooling, and housing quality were significant in all countries, with trends in the expected directions; i.e., increasing wealth and maternal education were associated with lower levels of infection, as was living in a house with finished windows and ceilings. Malaria prevalence decreased with urban residence and increased with child's age (Fig. 3) in all countries, as expected. These relationships were statistically significant in all countries but Rwanda, where the extremely low prevalence ( $2 \%)$ may play a role. Other covariates were significantly associated with prevalence in only some contexts. In seven of nine countries, children who slept under an ITN the previous night had lower parasitemia than those who did not, yet these differences were significant in only four countries. In Madagascar, parasitemia was significantly higher among such children, a surprising result which may reflect the mass distribution of nets to households in vulnerable regions. Household size was statistically significant in four countries; in each of these, and indeed in most countries, prevalence increased with the number of residents. No consistent patterns were observed for mother's age or sex of the household head, though each of these was significantly associated with risk in one-third of sampled countries.

Fig. 3. Prevalence of malaria parasitemia by child's age and country.

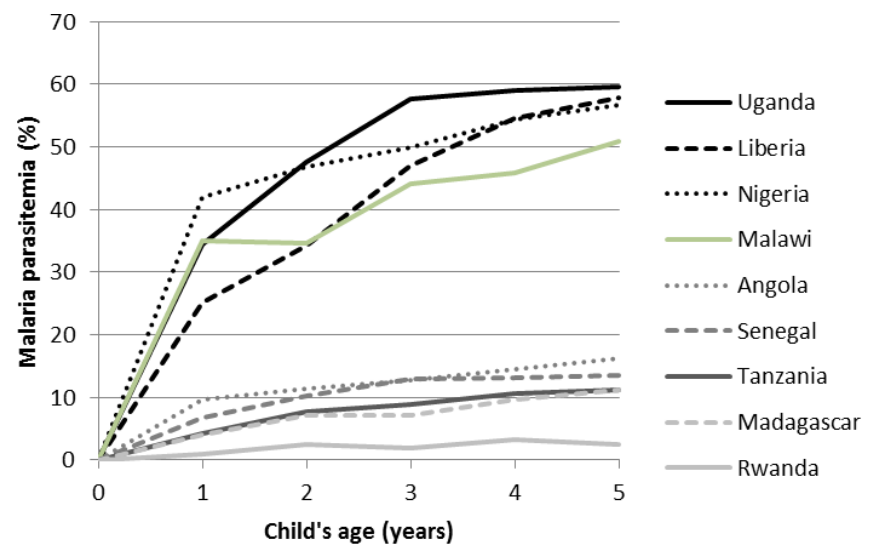

A simple way to assess associations of malaria with education and wealth is to look at parasitemia across different strata of these variables. Table 4 shows this relationship, both overall and delineated by urban/rural residence. For the complete sample, results were largely as expected. In almost every case, infection was highest where maternal education and household wealth were low, and was lowest in the high/high category, with high wealth and education each independently associated with decreased risk. 
Table 5. Odds ratios for malaria parasitemia in children from country-specific (IA) logistic regression models.

\begin{tabular}{|c|c|c|c|c|c|c|c|c|c|}
\hline Variable & $\begin{array}{l}\text { Angola } \\
(n=2900)\end{array}$ & $\begin{array}{l}\text { Liberia } \\
(n=2413)\end{array}$ & $\begin{array}{l}\text { Uganda } \\
(n=3400)\end{array}$ & $\begin{array}{l}\text { Malawi } \\
(n=1896)\end{array}$ & $\begin{array}{l}\text { Rwanda } \\
(n=3699)\end{array}$ & $\begin{array}{l}\text { Senegal } \\
(n=3562)\end{array}$ & $\begin{array}{l}\text { Tanzania } \\
(n=6612)\end{array}$ & $\begin{array}{l}\text { Nigeria } \\
(n=4353)\end{array}$ & $\begin{array}{l}\text { Madagascar } \\
(n=5257)\end{array}$ \\
\hline $\begin{array}{l}\text { Urban } \\
\text { residence } \\
\text { Mother's } \\
\text { highest level } \\
\text { of schooling } \\
\text { (vs. none) }\end{array}$ & $0.32 * * *$ & $0.71 * * *$ & $0.34 * * *$ & $0.36 * * *$ & 0.57 & $0.58 * * *$ & $0.46^{* *}$ & $0.60 * * *$ & $0.54^{*}$ \\
\hline Primary & 0.87 & 1.00 & 0.93 & 0.78 & $0.59^{*}$ & 0.99 & 1.00 & 1.10 & $1.37^{*}$ \\
\hline $\begin{array}{l}\text { Secondary+ } \\
\text { Wealth } \\
\text { quintile (vs. } \\
\text { lowest) }\end{array}$ & 1.04 & $0.67 * * *$ & $0.52 * * *$ & $0.47^{* * *}$ & 1.00 & 0.61 & $0.31^{* * *}$ & $0.73 * * *$ & 0.93 \\
\hline II & 1.10 & $0.77 *$ & 1.05 & 0.86 & 0.65 & 0.76 & 1.07 & 0.92 & 0.84 \\
\hline III & $0.57 * * *$ & 0.95 & 1.17 & $0.60 * * *$ & 0.56 & 0.90 & 0.88 & $0.80^{*}$ & $0.57 * * *$ \\
\hline IV & $0.30 * * *$ & $0.76^{*}$ & 1.00 & $0.58 * * *$ & $0.30 * *$ & $0.60 * *$ & $0.72 *$ & $0.57 * * *$ & $0.51 * * *$ \\
\hline V & $0.09 * * *$ & $0.52 * * *$ & $0.66^{* * *}$ & $0.25^{* * *}$ & $0.34^{*}$ & $0.53 * * *$ & $0.38 * * *$ & $0.46^{* * *}$ & $0.22 * * *$ \\
\hline
\end{tabular}

${ }^{*} p<0.05, * * p<0.01, * * * p<0.001$

There were two exceptions. In Uganda, among those with low maternal education, high wealth was associated with higher childhood infection than was low wealth; in Tanzania, among those with low wealth, high education was associated with marginally higher infection. In both cases, the differences in rates were small and nonsignificant. In the disjoint cases (low/high, high/low), high wealth was usually associated with a greater decrease in parasitemia than was high education. In seven of nine countries, the reduction in parasitemia associated with having both high wealth and high education exceeded the sum of the reductions from either alone.

A considerably more complex situation occurred when stratifying by urban residence. In urban areas, eight of nine countries deviated from the expected relationship; i.e., the high/high and low/low classes were not associated with the highest or lowest parasitemias, respectively. In most countries, small urban sample sizes and/or low rates of infection likely accounted for these patterns. In rural areas, observed values were more consistent with expectations, with a few exceptions. In rural Ugandans, among children with low education, high wealth was associated with higher prevalence than lower prevalence $(65.2 \%$ versus $54.8 \%)$. Among residents of rural Liberia, those with high education and wealth had the highest parasitemia, though the difference was small. Across residence strata, high wealth was more often (six of nine countries) associated with a greater decrease in parasitemia than was high education.

Table 5 shows odds ratios (ORs) for infection for urban residence, mother's educational attainment categories, and wealth quintiles from simple country-specific models (IA). The mean odds ratio for urban residence was 0.50 ; i.e., children living in urban areas experienced $50 \%$ lower odds of malaria infection relative to rural residents. Maternal schooling and household wealth were associated with monotonic decreases in odds of infection, as clearly shown in Fig. 2, although education was less often statistically significant than wealth. All significant odds ratios were less than 1.00, except in Madagascar, where completion of primary school was (surprisingly) associated with a $37 \%$ increase in risk, relative to no schooling. Being in the highest wealth quintile was associated with lower parasitemia, on average, than either high educational attainment or urban residence.

\section{Global logistic regression models}

The global hierarchical models estimate associations that are substantially similar to country-specific estimates. Model IIA included fixed effects for only urban residence, individual-level education and wealth, and country of survey, all of which were highly significant. Model IIB added cluster-level educational attainment and wealth; all variables remained highly significant except for community-level education, which was borderline significant. The magnitude of the associations of risk with individual-level SES and urban residence was reduced. Model IIC added polynomial terms for individual-level education and wealth, which further reduced the magnitude of correlations with urban residence and the other education variables. Because none of the interaction terms among the three main variables of interest (i.e., education * wealth, education * urban residence, and wealth * urban residence) attained statistical significance with the quadratic terms in the model, they were excluded from this and subsequent models. Model IID added covariates; both individual and cluster-level education lost significance, though education remained strongly associated with risk at the individual level because of the polynomial term. Child's age was, as expected, very strongly associated with risk (Fig. 3), while ITN use, but not housing quality, was associated with significant reductions in parasitemia. Increasing household size was significantly associated with increased risk, but mother's age and sex of the household head showed no significant relationships. Urban residence was associated with a large reduction in the odds of infection of close to $40 \%$, while having slept under an ITN the previous night accounted for a moderate reduction of $20 \%$.

\section{DISCUSSION}

In this sample derived from DHS/MIS data, maternal education, independently of household resources, was strongly associated with childhood malaria risk. Evaluated at the endpoints of their 
Table 6. Odds ratios and confidence intervals for malaria parasitemia in children from global hierarchical logistic regression models: minimal (IIA), incorporating cluster-level socioeconomic status factors (IIB), incorporating higher order terms (IIC), and full, incorporating all covariates (IID).

\begin{tabular}{|c|c|c|c|c|}
\hline & IIA & IIB & IIC & IID \\
\hline Urban residence & $0.34(0.28,0.40)^{* * *}$ & $0.48(0.40,0.57)^{* * *}$ & $0.53(0.44,0.63)^{* *}$ & $0.59(0.50,0.71)^{* * *}$ \\
\hline \multicolumn{4}{|l|}{$(\mathrm{EDU})$} & $0.990(0.971,1.009)$ \\
\hline $\mathrm{EDU}^{2}$ & - & - & $0.993(0.990,0.996) * * *$ & $0.993(0.990,0.996)^{* * *}$ \\
\hline Wealth percentile (WLT) & $0.986(0.984,0.988)^{* * *}$ & $0.991(0.989,0.994) * * *$ & $0.991(0.989,0.993)^{* * *}$ & $0.990(0.987,0.992) * * *$ \\
\hline $\mathrm{WLT}^{2}$ & - & - & $1.000(1.000,1.000)^{* * *}$ & $1.000(1.000,1.000)^{* * *}$ \\
\hline $\begin{array}{l}\text { Cluster-level educational attainment (mean } \\
\text { years) }\end{array}$ & - & $0.967(0.935,1.001)$ & $0.979(0.948,1.011)$ & $0.980(0.947,1.015)$ \\
\hline Cluster-level wealth percentile (mean) & - & $0.985(0.981,0.990)^{* * *}$ & $0.985(0.981,0.990)^{* * *}$ & $0.984(0.979,0.988) * * *$ \\
\hline Child's age (months) & - & - & - & \\
\hline $6-11$ & & & & REF \\
\hline $12-23$ & & & & $2.22(1.88,2.62)^{* * *}$ \\
\hline $24-35$ & & & & $3.70(3.12,4.37)^{* * *}$ \\
\hline $36+$ & & & & $5.00(4.25,5.87)^{* * *}$ \\
\hline Child slept under insecticide-treated bednet & - & - & - & $0.80(0.72,0.88)^{* * *}$ \\
\hline Finished windows and ceilings & - & - & - & $0.93(0.81,1.07)$ \\
\hline Household size & - & - & - & \\
\hline $1-4$ & & & & REF \\
\hline $5-6$ & & & & $1.11(0.97,1.27)$ \\
\hline $7-8$ & & & & $1.16(0.99,1.35)$ \\
\hline $9+$ & & & & $1.46(1.24,1.73)^{* * *}$ \\
\hline Mother's age (years) & - & - & - & \\
\hline$<20$ & & & & REF \\
\hline $20-29$ & & & & $1.05(0.85,1.30)$ \\
\hline $30-39$ & & & & $0.92(0.74,1.14)$ \\
\hline $40+$ & & & & $1.07(0.83,1.38)$ \\
\hline Female head of household & - & - & - & $1.09(0.95,1.24)$ \\
\hline \multicolumn{5}{|l|}{ Country } \\
\hline Angola & REF & REF & REF & REF \\
\hline Liberia & $33.71(24.63,46.12) * * *$ & $33.80(24.86,45.97)^{* * *}$ & $28.13(21.48,36.82)^{* * *}$ & $41.20(30.27,56.07)^{* * *}$ \\
\hline Uganda & $28.69(21.26,38.71)^{* * *}$ & $32.20(23.85,43.48)^{* * *}$ & $25.24(19.47,32.71)^{* * *}$ & $40.15(29.74,54.20)^{* * *}$ \\
\hline Malawi & $12.84(9.61,17.15)^{* * *}$ & $13.90(10.36,18.64)^{* * *}$ & $11.63(8.91,15.17)^{* * *}$ & $16.68(12.38,22.48)^{* * *}$ \\
\hline Rwanda & $0.12(0.08,0.16)^{* * *}$ & $0.13(0.09,0.18)^{* * *}$ & $0.12(0.09,0.17)^{* * *}$ & $0.15(0.10,0.21)^{* * *}$ \\
\hline Senegal & $0.95(0.74,1.22)$ & $0.99(0.76,1.28)$ & $1.07(0.84,1.37)$ & $1.01(0.77,1.32)$ \\
\hline Tanzania & $0.63(0.59,0.81)^{* *}$ & $0.72(0.56,0.93)^{*}$ & $0.65(0.51,0.82)^{* *}$ & $0.82(0.63,1.07)$ \\
\hline Nigeria & $27.1(20.18,36.27)^{* * *}$ & $28.62(21.34,38.37)^{* * *}$ & $25.34(19.55,32.83)^{* * *}$ & $31.91(23.86,42.67)^{* * *}$ \\
\hline Madagascar & $0.35(0.28,0.45) * * *$ & $0.38(0.30,0.49)^{* * *}$ & $0.39(0.31,0.49)^{* * *}$ & $0.73(0.57,0.94)^{*}$ \\
\hline
\end{tabular}

ranges, the magnitude of the association between higher maternal education and lower malaria risk in children was smaller than the equivalent association for household resources, yet it was still substantial and statistically significant. Controlling for other factors, completion of six years of primary school by the mother was associated with a reduction in the odds of malaria infection in her child of about $27 \%(\mathrm{OR}=0.73)$, whereas an increase from the lowest wealth percentile to the 40th (equivalent to the lower end of the middle wealth quintile) correlated to a $52 \%$ reduction in risk $(\mathrm{OR}=0.48)$. The absolute values of these figures appear to lie within the range observed in previously published data, although precise comparisons are difficult because the measures used and outcomes vary widely across studies. For example, Somi et al. (2007) found a one-unit increase in asset-based wealth PCA score - where the range of PCA scores across all individuals was 11.1 - to decrease parasitemia by $4 \%$. Siri et al. (2010) estimated a $10 \%$ increase in wealth percentile to be associated with a $20 \%$ reduction in risk of malarial anemia risk in an urban area.
Importantly, it was not possible to evaluate the role of paternal education because these surveys do not specifically identify fathers. Yet this variable is likely to also play a major role, especially where fathers are ultimately responsible for healthseeking decisions. Prior work has shown that paternal schooling may be a strong predictor of investment in children - in some contexts, a better predictor than maternal schooling (e.g., Behrman and Rosenzwieg 2001). To some extent, the effects attributed in this study to maternal education are likely be partly the result of paternal education, with which it is usually highly correlated. A variable linking children to data on their fathers would be a useful addition to future MIS studies.

The inclusion of higher order terms is rare in analyses of sociodemographic or contextual risk factors for malaria, yet such relationships are quite likely. A small increase in resources may make a great deal of difference to a poor household in terms of its ability to provide in ways that reduce a child's malaria risk, while a similar increase may make little difference for wealthy 
households that already make use of available malaria prevention and treatment opportunities. In the same vein, a few years of education at the primary level, in addition to (perhaps) providing knowledge about malaria, are likely to boost basic life skills, familiarity with and trust in the public health system, self-reliance, and a host of other factors that affect risk, whereas a few extra post-secondary years may be of lesser import. Conversely, there may be certain thresholds of educational attainment or wealth below which increases have little effect on ability or propensity to mitigate risk. Similarly, interactions among wealth, education, and urban context are to be expected. For example, the ability of individuals to make use of their knowledge and skills should, in fact, depend on their economic resources, and vice versa. The extent to which mothers are able to capitalize on education or wealth may depend on the distance to or the absolute availability of prevention or control measures or other factors which may vary significantly across levels of urbanization. In this study, small but significant nonlinearities were observed in the associations between the logit of malaria parasitemia and wealth and education. In particular, risk decreased with increasing SES terms but also with the squared terms, implying that the effects of these factors (to the extent that these reflect causal relationships) increase at higher levels. Nonlinear effects can result from interactions or from polynomial relationships of the outcome with particular independent variables, or both. This model attributes these to the latter, but a different model selection process might specify a greater role for interaction terms. Nevertheless, observed effect sizes were small, and the main results were relatively insensitive to the choice of higher order terms.

The model specified in this study improves upon previous uses of DHS data to evaluate the association of malaria risk with SES factors by incorporating confirmed parasitemia rather than selfreported fever (as in Filmer 2005) and by separating out the independent effect of education. It complements prior studies with DHS (Fuchs et al. 2010, Pamuk et al. 2011) that have demonstrated a significant association of maternal education, independent of wealth, with infant mortality. In the latter, education was generally found to be more reliably and strongly associated with health than was wealth, whereas the current results suggest the opposite. It may be that infant mortality encapsulates such a range of disease syndromes and potential risk factors that the ability of mothers to flexibly apply knowledge and skills is more important than for malaria, where interventions are generally well defined but often costly. Moreover, the dramatic acceleration in efforts to combat malaria in the African continent over the past decade would, in some cases, have saturated surveyed populations with information on malaria causes, prevention, and treatment, yet in some situations, schooling may confer a relative advantage through the transmission of just such knowledge (e.g., malaria education modules or general instruction on health and hygiene). In such contexts, these "direct" benefits of maternal education would have been dampened (though more distal effects, such as increased self-reliance, would not have been affected).

This study also presents novel information from DHS/MIS on associations of cluster-level maternal education and household wealth with malaria parasitemia. In particular, cluster-level wealth was found to have a slightly stronger association with risk than was individual-level wealth, which potentially bespeaks the role of community-level infrastructure or services. Cluster-level education exhibited a similar inverse relationship with malaria risk, as did individual-level education, but this did not attain significance in the model. This work should be considered preliminary for various reasons. First, different ways of parameterizing community-level education, incorporating all adults rather than just women, or all women rather than just mothers, would likely yield different results; such alternative parameterizations would speak to different hypotheses about the role of community-level knowledge. Second, cluster means are based on relatively few respondents, with a small fraction $(7.8 \%)$ containing less than five individuals. Because some households contained multiple respondents, cluster-level means will in some cases have been constructed from just one or two households. Analyses based on larger aggregations might arrive at conclusions that differ from or supplement those found in this study for individuals and clusters. The main reason that the elucidation of community-level (or broader geographic) effects has not been undertaken is that the selection of areas over which to evaluate areal associations is not straightforward. Aggregating clusters in a way that accurately reflects endemic, environmental, cultural, economic, or policy boundaries requires a greater knowledge of local context than is available to a secondary analysis of DHS/ MIS data. Ideally, it requires access to fine geographic data on sampling locations, maps of endemicity, and detailed local knowledge about, for example, school systems, health catchment areas, geographic aspects of public health action, consumption patterns, and tribal, neighborhood, or other cultural boundaries. This would be a useful area for future work.

As expected, urban residence was strongly associated with malaria risk: urban residents were about $40 \%$ less likely $(\mathrm{OR}=0.59)$ to be infected, after controlling for other factors. Broad evidence exists for the reduction of malaria prevalence in cities (Robert et al. 2003, Keiser et al. 2004, Hay et al. 2005). An effort to relate $P$. falciparum prevalence to urban extents at the global scale found the median parasite rate in urban areas to be about $40 \%$ that in rural areas (Tatem et al. 2008), and two other studies using MIS data estimated similar odds ratios for urban residence: 0.42 in Tanzania (Gosoniu et al. 2012) and 0.43 in Senegal (Giardina et al. 2012), though this relationship was statistically significant only in the former. These reductions are greater than those observed in the final model in this study but are similar to what is seen in the reduced model $(\mathrm{OR}=0.34)$. It may be that the variables representing community-level wealth and/or housing quality capture some of the variation that would otherwise be attributable to urban residence. The country-specific regressions estimated in this study show substantial variation in the association of malaria with urbanization across countries $(\mathrm{OR}=0.32-0.71)$ (Table 5). An important way forward in further specifying the effect of contextual risk factors will be to link the GPS locations of sampled clusters to continent-wide maps of population distribution and malaria endemicity.

When controlling for other factors, sleeping under an ITN was associated with $\sim 20 \%$ reduction in the odds of malaria parasitemia prevalence. This is close to the level observed in a study that used very similar DHS/MIS data to that presented here. Lim et al. (2011) found a pooled mean reduction in prevalence of $24 \%$ in children who slept under an ITN. The small difference in estimated effect may arise from the inclusion of different countries/surveys in the overall data set (e.g., Lim et al. [2011] 
used data for Zambia but not Malawi, Nigeria, or Madagascar in estimating effects on parasitemia prevalence) or the specification of different covariates (e.g., Lim et al. [2011] used the original DHS wealth index and did not include housing quality). In the final model, housing quality (i.e., the presence of finished walls and ceilings) was not significantly associated with risk - a surprising result, given a priori expectations and the strong relationships observed at the bivariate level. It may be that the cluster-level wealth variable captured some of the variation that would have otherwise been attributable to housing quality. ITNs and quality housing both act as barriers to transmission while sleeping in the household; however, ITNs also act by killing resting mosquito vectors, so it is consistent with theory that this association is larger in magnitude.

A significant association of malaria risk with increased household size was observed, particularly at the largest sizes. Children from households with nine or more individuals were almost $50 \%$ more likely $(\mathrm{OR}=1.46)$ to have malaria. The effect of household size is likely complex: a greater number of individuals per sleeping room may reduce the chances of an individual being bitten by a mosquito but may also decrease an individual's likelihood of having access to a bednet. Generally, larger households have more resources at their disposal; however, since malaria is infectious, the presence of more people in close proximity may lead to a higher probability of locally infected mosquitoes, and thus transmission. Risk may also depend on the composition of household members or on the number of people in particular age groups rather than overall household size. For example, in a multilevel analysis in Ethiopia, Peterson et al. (2009) found the number of children aged 5-9 years was a strong predictor (IRR $=1.66$ ) of household risk. Unlike some previous studies, no significant associations were found for mother's age or the sex of the household head, nor did their inclusion appreciably affect estimates for associations with wealth or education.

This study identified strong independent associations of education with malaria risk when using confirmed malaria parasitemia in a range of countries across sub-Saharan Africa and when controlling for other SES factors. Education is valuable in its own right as a critical element of self-determination, human rights, and social justice, but this study provides more evidence that it also is an important determinant of health. It is worth noting that the effects of education on malaria prevalence extend beyond simply the acquisition of knowledge. Indeed, other studies (e.g., Safeukui-Noubissi et al. 2004) have noted that education lowers malaria risk even where specific knowledge is lacking. Likely, education encompasses less tangible factors such as selfsufficiency, motivation, and confidence, which can lead to improved outcomes on a broad front.

There are important reasons to consider the effects of education on malaria prevalence and incidence. For one, policies to promote education are often substantially different from those aimed at reducing poverty or at controlling malaria in the short term, yet such policies may yield important cobenefits for malaria control. Indeed, other work has shown that rising standards of living, including education and consequent shifts in occupation, are in many contexts a precursor - if not a precondition - for malaria elimination (Humphreys 2001). Second, the provision of education has an inertia, inculcating skills and intangible factors in the recipient that have a persistency that does not exist for other interventions (Lutz 2009). Malaria control is too often envisioned as a response to immediate or short-term needs, and resurgence often follows the reduction or cessation of activities. Economic resources, too, are subject to considerable variation at household, community, and national scales, whereas education, once attained, is long lasting (though skills and knowledge may eventually wane), with effects that are felt for decades - even when funding ceases. Given the current shortfalls in funding for global malaria control and the lingering effects of the global financial crisis, it makes sense to add measures that act over the long term to the arsenal of malaria control tools - with due consideration, of course, for cost-effectiveness, the time horizon of expected benefits, and potential opportunity costs. Third, among research needs that have been identified as being critically important as countries move to lower prevalence is a better understanding of distributional aspects of malaria (Marsh 2010); it seems likely that maternal education significantly influences such distributions. Finally, beyond the potential for maternal education as a policy lever for combating malaria, our results suggest the utility of including it as a factor in projections of future endemicity and health costs. In other contexts, it has been shown that taking account of educational attainment in multistate projection models of specific health outcomes leads to significantly different conclusions about the health and needs of future populations (Batljan et al. 2009, Loichinger 2012). If the current climate of optimism and relatively high funding does not lead to the highly anticipated elimination of malaria in much of the world, it may well be that ensuring education for women yields substantial and lasting reductions in prevalence in some situations.

Among the main limitations of this work are the potential for unobserved or excluded variables or endogeneity to generate spurious findings, misspecification in variable construction or ascertainment, unmodeled dependence among observations, and differential recall of information by sampled subgroups.

As with most observational studies of SES factors, endogeneity (i.e., a situation where the values of some factors in the system are partially or wholly determined by the state of other system variables) is almost inevitably a feature in the data used in this study. Each of the three main variables of interest (education, wealth, urban residence) can plausibly be caused, in part, by the other two. Education may affect earning potential and residential preferences; household wealth can determine the ability to pay for education and afford housing. Urban versus rural residence may affect the quality of schooling, salaries, and cost of living. Furthermore, each may affect and be affected by malaria prevalence. Other covariates, such as bednet use or housing quality, are also likely to be endogenous - i.e., on the causal chain from SES to malaria risk. When endogeneity is present, unidirectional studies are likely to overstate the influence of risk factors. This is a problem that has been less extensively considered in the epidemiologic than in the economic literature, and more detailed work on this problem in the context of malaria risk is called for.

In particular, more studies along the lines of Somi et al. (2007) and de Castro and Fisher (2012) are needed to evaluate the direction of causality in the relationships between SES and 
malaria, but, as the results of this study suggest, this should be assessed for maternal education in addition to (and separately from) wealth. Moreover, it is not clear that the particular instrumental variables used in prior studies are appropriate for most contexts. For example, Somi et al. (2007) used education of the household head and region of residence as instruments for SES, and de Castro and Fisher (2012) used variables related to household size. From the perspective of this study, none of those would be appropriate due to their associations with malaria risk. It is unclear what set of exogenous variables from DHS/MIS surveys might serve as appropriate instruments that would be valid across all the country contexts examined, and such approaches are more likely to be fruitful in narrower contexts. Yet, comparative cross-sectional studies can still have utility, even when endogeneity is present, by drawing attention to important relationships and by suggesting hypotheses that need further development, as is done in this study.

Although reverse or simultaneous causality is likely in the data used in this study, it is probable that causality in the expected direction also applies; i.e., it is reasonable to suppose that household wealth, which reflects assets built up over the long term rather than instantaneous availability of funds, precedes and influences acute infection in the child. This is even more true for maternal educational attainment, which in most cases will have predated the child's birth, and it is also true for urban residence and housing, and potentially for many other factors. Yet, to the extent that infection in the child reflects risk to other members of the household, the long-term pattern of infection may indeed influence SES factors in this context. Moreover, unobserved factors almost certainly complicate the relationship between education and risk. Innate parental ability, for example, may influence both likelihood of attending school and actions to prevent malaria in children.

Considerable potential for misclassification exists within the DHS/MIS data. Wealth, in particular, is difficult to measure or even accurately to conceptualize in comparative studies. It is not necessarily clear whether the resources most likely to affect health are the immediate availability of funds for acute care or long-term assets and stability, which affect nutrition, education, and many other factors. Moreover, assets owned vary considerably from country to country and from rural to urban areas, such that indices that attempt to capture multiple settings likely misclassify a substantially large proportion of households. The wealth-based asset index, nevertheless, has become a standard tool for crosscountry comparisons. Results using asset indices compare favorably with direct measures of household consumption or other economic indicators (Filmer and Scott 2012) and are usually much easier to obtain. Aggregating household wealth at the cluster level based on the responses of mothers may also lead to misclassification of the community resources that are most likely to influence child risk; therefore, alternative parameterizations, as well as larger aggregations, should be explored. Educational content and quality, too, vary across countries and regions within countries, such that equating years of schooling for all respondents is likely to be misleading. It would be of interest to consider more comparable outcomes such as literacy, numeracy, or malaria-specific knowledge; the latter, in particular, was not possible in this study because not all the DHS/MIS data sets included such questions. ITN use may have substantially different implications depending on the specific measure used (e.g., sleeping under an ITN the previous night versus household ITN ownership), though Lim et al. (2011) found nearly identical effects for these two predictors when they used DHS/MIS data. Housing made of finished materials may or may not have open eaves, which allow for mosquito entry and thus infection (Lindsay and Snow 1988). Despite the potential for misclassification, an effort has been made, where possible, to show that the results presented here are plausible and comparable to previous work.

A potentially greater problem is misspecification of the model through the failure to include all relevant variables. The goal in this study was to demonstrate the independent association of maternal education with malaria risk, and a conservative set of explanatory variables was adopted for simplicity and clarity, and to maximize the number of observations relative to independent variables. Yet, a wide range of other variables that affect malaria risk are potentially available in some DHS/MIS data sets, and others could be associated through Geographic Information System/Remote Sensing analyses or the collection of nationallevel health system, education, or economic data. Among variables of potential interest are community-level endemicity and environmental factors, recent household insecticide residual spraying, behavioral factors related to malaria prevention and control, and economic or policy factors at regional or national scales. Further work should incorporate these variables for a wider range of DHS/MIS surveys. Indeed, a major limiting factor in this analysis was the availability of only 13 of the 32 studies that have collected data on malaria parasitemia (Fig. 1-several countries have completed more than one survey). The timely release of other data sets relevant to malaria risk is critical to conducting effective research. Other variables of potential importance were not included or easily derivable from DHS/MIS data-for example, paternal education or frequency of travel to high-risk areas, which has been identified as a significant risk factor in some contexts (Siri et al. 2010).

The hierarchical multilevel model employed in this study accounts for the nonindependent nature of data collected at cluster and household levels, and for the fixed effects of country of survey. However, within households, some mothers contributed more than one child to the survey sample. This source of variation is unmodeled in this study, and could lead to biased parameter estimates. Most of this variation is likely accounted for by the incorporation of household-level random effects.

Finally, there is the possibility that differential recall or reporting of SES factors between the more and less educated/wealthy could bias the results. Those with a better understanding of the causes of malaria or more direct exposure to, for example, information campaigns, may be more likely to identify factors that contribute to illness in their families, which could lead to an overestimation of the effect of risk factors in this context. Such an effect may have contributed to the unusually high prevalence observed among those with high education but low wealth in Uganda, though small sample sizes probably played a role.

\section{CONCLUSION}

The main finding of this study is that maternal education and household wealth are each independently associated with lower malaria parasitemia in children, though the magnitude of the relationship tends to be larger for household wealth. Urban 
residence was associated with a greater reduction in risk than was any other factor, with malaria risk in urban dwellers $\sim 40 \%$ lower than in rural dwellers. ITN use was associated with moderately decreased risk, but no significant effect was found for high-quality housing. Large household size $(9+)$ was associated with a significant increase in malaria prevalence in children. These findings have important implications for projections of the longterm prevalence of disease and for the policy discourse surrounding malaria control and prevention. Future research on socioeconomic determinants of malaria risk should clearly distinguish between the effects of education and wealth, seek to establish the causality of the relationships involved, and evaluate the extent to which interactions among these factors and others like endemicity and community-level variables affect risk. DHS/ MIS data can be useful in this regard, especially as more MIS studies are released for research purposes, but other data that evaluate quality of education and examine the multiple pathways via which SES factors affect risk are needed.

Responses to this article can be read online at: http://www.ecologyandsociety.org/issues/responses. $\mathrm{php} / 6134$

\section{Acknowledgments:}

Extensive thanks are due to all those whose insights contributed to this work. Wolfgang Lutz provided guidance and important input on study design and the interpretation of findings. Regina Fuchs and Lia Florey offered advice on working with DHS and SES data. Daniela Weber and Collin Payne were helpful in designing and interpreting the multilevel modeling process. This study was funded by IIASA's World Population Program, whose staff, including particularly Bill Butz, Stephanie Andruchowitz, and Katja Scherbov, provided institutional support, as did Helmut Klarn and Jaro Chovanec. Two reviewers provided insightful comments and criticisms that strongly contributed to the development and value of this study.

\section{LITERATURE CITED}

Aldrich, J. H., and F. D. Nelson. 1984. Linear probability, logit, and probit models. SAGE Publications, Inc., Newbury Park, California, USA.

Barat, L. M., N. Palmer, S. Basu, E. Worrall, K. Hanson, and A. Mills. 2004. Do malaria control interventions reach the poor? A view through the equity lens. American Journal of Tropical Medicine and Hygiene 71:174-178.

Batljan, I., M. Lagergren, and M. Thorslund. 2009. Population ageing in Sweden: the effect of change in educational composition on the future number of older people suffering severe ill-health. European Journal of Ageing 6:201-211. http://dx.doi.org/10.1007/ s10433-009-0120-1

Behrman, J., and M. R. Rosenzweig. 2001. Does increasing women's schooling raise the schooling of the next generation? American Economic Review 92(1):323-334. http://dx.doi. org/10.1257/000282802760015757
Box, G. E. P., and P. W. Tidwell. 1962. Transformation of the independent variables. Technometrics 4:531-550. http://dx.doi. org/10.1080/00401706.1962.10490038

Boyle, M. H., Y. Racine, K. Georgiades, D. Snelling, S. Hong, W. Omariba, P. Hurley, and P. Rao-Melacini. 2006. The influence of economic development level, household wealth and maternal education on child health in the developing world. Social Science and Medicine 63:2242-2254.

Carme, B., H. Plassart, P. Senga, and S. Nzingoula. 1994. Cerebral malaria in African children: socioeconomic risk factors in Brazzaville, Congo. American Journal of Tropical Medicine and Hygiene 50:131-136.

Chima, R. I., C. A. Goodman, and A. Mills. 2003. The economic impact of malaria in Africa: a critical review of the evidence. Health Policy 63:17-36. http://dx.doi.org/10.1016/S0168-8510 (02)00036-2

Cibulskis, R. E., M. Aregawi, R. Williams, M. Otten, and C. Dye. 2011. Worldwide incidence of malaria in 2009: estimates, time trends, and a critique of methods. PLoS Medicine 8:e1001142. http://dx.doi.org/10.1371/journal.pmed.1001142

Cohen, J. M., D. L. Smith, C. Cotter, A. Ward, G. Yamey, O. J. Sabot, and B. Moonen. 2012. Malaria resurgence: a systematic review and assessment of its causes. Malaria Journal 11:122. http://dx.doi.org/10.1186/1475-2875-11-122

Cosep Consultoria, Consaúde e ICF Macro. 2011. Inquérito de Indicadores de Malária em Angola de 2011. Cosep Consultoria, Consaúde e ICF Macro, Calverton, Maryland, USA.

Custodio, E., M. Descalzo, E. Villamor, L. Molina, I. Sánchez, M. Lwanga, C. Bernis, A. Benito, and J. Roche. 2009. Nutritional and socio-economic factors associated with Plasmodium falciparum infection in children from Equatorial Guinea: results from a nationally representative survey. Malaria Journal 8:225. http://dx.doi.org/10.1186/1475-2875-8-225

Das, P., and R. Horton. 2010. Malaria elimination: worthy, challenging, and just possible. Lancet 376:1515-1517. http://dx. doi.org/10.1016/S0140-6736(10)61551-6

de Castro, M., and M. Fisher. 2012. Is malaria illness among young children a cause or a consequence of low socioeconomic status? Evidence from the United Republic of Tanzania. Malaria Journal 11:161. http://dx.doi.org/10.1186/1475-2875-11-161

de Souza, A. C. T., E. Cufino, K. E. Peterson, J. Gardner, M. I. V. Do Amaral, and A. Ascherio. 1999. Variations in infant mortality rates among municipalities in the state of Ceará Northeast Brazil: an ecological analysis. International Journal of Epidemiology 28:267-275. http://dx.doi.org/10.1093/ije/28.2.267

D'Souza, B. J., and R. D. Newman. 2012. Strengthening the policy setting process for global malaria control and elimination. Malaria Journal 11:28. http://dx.doi.org/http://dx.doi. org/10.1186/1475-2875-11-28

Eisele, T. P., D. A. Larsen, N. Walker, R. E. Cibulskis, J. O. Yukich, C. M. Zikusooka, and R. W. Steketee. 2012. Estimates of child deaths prevented from malaria prevention scale-up in Africa 2001-2010. Malaria Journal 11:93. http://dx.doi.

org/10.1186/1475-2875-11-93 
Feachem, S., and M. Sabot. 2008. A new global malaria eradication strategy. Lancet 371:1633-1635. http://dx.doi. org/10.1016/S0140-6736(08)60424-9

Filmer, D. 2005. Fever and its treatment among the more and less poor in sub-Saharan Africa. Health Policy and Planning 20:337346. http://dx.doi.org/10.1093/heapol/czi043

Filmer, D., and L. H. Pritchett. 2001. Estimating wealth effects without expenditure data - or tears: an application to educational enrollments in states of India. Demography 38:115-132.

Filmer, D., and K. Scott. 2012. Assessing asset indices. Demography 49:359-392. http://dx.doi.org/10.1007/s13524-011-0077-5

Fuchs, R., E. Pamuk, and W. Lutz. 2010. Education or wealth: Which matters more for reducing child mortality in developing countries? Vienna Yearbook of Population Research 8:175-199. http://dx.doi.org/http://dx.doi.org/10.1553/populationyearbook2010s175

Gakidou, E., K. Cowling, R. Lozano, and C. J. Murray. 2010. Increased educational attainment and its effect on child mortality in 175 countries between 1970 and 2009: a systematic analysis. Lancet 376:959-974. http://dx.doi.org/10.1016/S0140-6736(10) 61257-3

Gallup, J. L., and J. D. Sachs. 2001. The economic burden of malaria. American Journal of Tropical Medicine and Hygiene 64:85-96.

Gates Foundation. 2007. Bill and Melinda Gates call for new global commitment to chart a course for malaria eradication. [online] URL: http://www.gatesfoundation.org/Media-Center/ Press-Releases/2007/10/Chart-a-Course-for-Malaria-Eradication

Gemperli, A., P. Vounatsou, I. Kleinschmidt, M. Bagayoko, C. Lengeler, and T. Smith. 2004. Spatial patterns of infant mortality in Mali: the effect of malaria endemicity. American Journal of Epidemiology 159:64-72. http://dx.doi.org/10.1093/aje/kwh001

Geyer, S., Ö. Hemström, R. Peter, and D. Vågerö. 2006. Education, income, and occupational class cannot be used interchangeably in social epidemiology. Empirical evidence against a common practice. Journal of Epidemiology \& Community Health 60:804-810. http://dx.doi.org/10.1136/ jech.2005.041319

Giardina, F., L. Gosoniu, L. Konate, M. B. Diouf, R. Perry, O. Gaye, O. Faye, and P. Vounatsou. 2012. Estimating the burden of malaria in Senegal: Bayesian zero-inflated binomial geostatistical modeling of the MIS 2008 data. PLOS ONE 7:e32625. http://dx. doi.org/10.1371/journal.pone.0032625

Gosoniu, L., A. Msengwa, C. Lengeler, and P. Vounatsou. 2012. Spatially explicit burden estimates of malaria in Tanzania: Bayesian geostatistical modeling of the malaria indicator survey data. PLOS ONE 7:e23966. http://dx.doi.org/10.1371/journal. pone.0023966

Gosoniu, L., A. M. Veta, and P. Vounatsou. 2010. Bayesian geostatistical modeling of malaria indicator survey data in Angola. PloS One 5:e9322. http://dx.doi.org/10.1371/journal. pone.0009322

Hay, S. I., C. A. Guerra, A. J. Tatem, P. M. Atkinson, and R. W. Snow. 2005. Tropical infectious diseases: urbanization, malaria transmission and disease burden in Africa. Nature Reviews Microbiology 3:81-90. http://dx.doi.org/10.1038/nrmicro1069

Humphreys, M. 2001. Malaria: poverty, race, and public health in the United States. Johns Hopkins University Press, Baltimore, Maryland, USA.

ICF International. 2012. Demographic and health survey sampling and household listing manual. ICF International, MEASURE DHS, Calverton, Maryland, USA.

Kazembe, L. N., C. C. Appleton, and I. Kleinschmidt. 2007. Spatial analysis of the relationship between early childhood mortality and malaria endemicity in Malawi. Geospatial Health 2:41-50.

Keiser, J., J. Utzinger, M. Caldas de Castro, T. A. Smith, M. Tanner, and B. H. Singer. 2004. Urbanization in sub-Saharan Africa and implication for malaria control. American Journal of Tropical Medicine and Hygiene 71:118-127.

Kiernan, K., J. Tao, and P. Gibbs. 2012. Tips and strategies for mixed modeling with SAS/STAT ${ }^{\circledR}$ procedures. SAS Institute, Cary, North Carolina, USA.

Koram, K. A., S. Bennett, J. H. Adiamah, and B. M. Greenwood. 1995a. Socio-economic risk factors for malaria in a peri-urban area of the Gambia. Transactions of the Royal Society of Tropical Medicine \& Hygiene 89:146-150. http://dx.doi.org/ http://dx.doi. org/10.1016/0035-9203(95)90471-9

Koram, K. A., S. Bennett, J. H. Adiamah, and B. M. Greenwood. 1995b. Socio-economic determinants are not major risk factors for severe malaria in Gambian children. Transactions of the Royal Society of Tropical Medicine \& Hygiene 89:151-154. http://dx. doi.org/http://dx.doi.org/10.1016/0035-9203(95)90472-7

Lim, S. S., N. Fullman, A. Stokes, N. Ravishankar, F. Masiye, C. J. L. Murray, and E. Gakidou. 2011. Net benefits: a multicountry analysis of observational data examining associations between insecticide-treated mosquito nets and health outcomes. PLoS Medicine 8:e1001091. http://dx.doi.org/10.1371/journal.pmed.1001091

Lindsay, S. W., and R. W. Snow. 1988. The trouble with eaves; house entry by vectors of malaria. Transactions of the Royal Society of Tropical Medicine \& Hygiene 82:645-646. http://dx. doi.org/10.1016/0035-9203(88)90546-9

Loichinger, E. 2012. Europe's future human capital: population projections by age, sex, education, labor force participation and health status. Dissertation. Vienna University of Economics and Business, Vienna, Austria.

Luckner, D., B. Lell, B. Greve, L. G. Lehman, R. J. Schmidt-Ott, P. Matousek, K. Herbich, D. Schmid, R. Mba, and P. G. Kremsner. 1998. No influence of socioeconomic factors on severe malarial anaemia, hyperparasitaemia or reinfection. Transactions of the Royal Society of Tropical Medicine \& Hygiene 92:478-481. http://dx.doi.org/10.1016/S0035-9203(98)90882-3

Lutz, W. 2009. Sola schola et sanitate: human capital as the root cause and priority for international development? Philosophical Transactions of the Royal Society B: Biological Sciences 364:30313047. http://dx.doi.org/http://dx.doi.org/10.1098/rstb.2009.0156 
Malaria Elimination Group. 2009. Shrinking the malaria map: a prospectus on malaria elimination. R. G. A. Feachem, A. A. Phillips, and G. A. Targett, editors. The Global Health Group, UCSF Global Health Sciences, San Francisco, California, USA.

Marsh, K. 2010. Research priorities for malaria elimination. Lancet 376:1626-1627. http://dx.doi.org/10.1016/S0140-6736 (10)61499-7

MeasureDHS. 2013. MEASURE DHS Demographic and health surveys. [online] URL: http://www.measuredhs.com/

Mendis, K., A. Rietveld, M. Warsame, A. Bosman, B. Greenwood, and W. H. Wernsdorfer. 2009. From malaria control to eradication: the WHO perspective. Tropical Medicine \& International Health 14:802-809. http://dx.doi.org/10.1111/ j.1365-3156.2009.02287.x

Moonen, B., J. M. Cohen, R. W. Snow, L. Slutsker, C. Drakeley, D. L. Smith, R. R. Abeyasinghe, M. H. Rodriguez, R. Maharaj, M. Tanner, and G. Targett. 2010. Operational strategies to achieve and maintain malaria elimination. Lancet 376:1592-1603. http:// dx.doi.org/10.1016/S0140-6736(10)61269-X

Morel, C. M., J. A. Lauer, and D. B. Evans. 2005. Cost effectiveness analysis of strategies to combat malaria in developing countries. BMJ (Clinical research ed.) 331:1299. http://dx.doi.org/10.1136/bmj.38639.702384.AE

Nájera, J. A., M. González-Silva, and P. L. Alonso. 2011. Some lessons for the future from the global malaria eradication programme (1955-1969). PLoS Medicine 8:e1000412. http://dx. doi.org/10.1371/journal.pmed.1000412

National Institute of Statistics of Rwanda (Rwanda), Ministry of Health (Rwanda), and ICF International. 2012. Rwanda demographic and health survey 2010. Calverton, Maryland, USA.

National Malaria Control Program (Liberia), Ministry of Health and Social Welfare, Liberia Institute of Statistics and GeoInformation Services, and ICF International. 2012. Liberia malaria indicator survey 2011. Monrovia, Liberia.

National Malaria Control Programme (Malawi) and ICF International. 2012. Malawimalaria indicator survey (MIS) 2012. Lilongwe, Malawi and Calverton, Maryland, USA.

National Population Commission (Nigeria), National Malaria Control Programme (Nigeria), and ICF International. 2012. Nigeria malaria indicator survey 2010. Abuja, Nigeria.

Ndiaye, S., and M. Ayad. 2009. Enquête Nationale sur le Paludisme au Sénégal 2008-2009. Centre de Recherche pour le Développement Humain [Sénégal] et ICF Macro, Calverton, Maryland, USA.

Noor, A. M., J. A. Omumbo, A. A. Amin, D. Zurovac, and R. W. Snow. 2006. Wealth, mother's education and physical access as determinants of retail sector net use in rural Kenya. Malaria Journal 5:5. http://dx.doi.org/http://dx.doi.org/10.1186/1475-2875-5-5

Ong'echa, J. M., C. C. Keller, T. Were, C. Ouma, R. O. Otieno, Z. Landis-Lewis, D. Ochiel, J. L. Slingluff, S. Mogere, G. A. Ogonji, A. S. Orago, J. M. Vulule, S. S. Kaplan, R. D. Day, and D. J. Perkins. 2006. Parasitemia, anemia, and malarial anemia in infants and young children in a rural holoendemic Plasmodium falciparum transmission area. American Journal of Tropical Medicine and Hygiene 74:376-385.

Packard, R. M. 2009. "Roll back malaria, roll in development"? Reassessing the economic burden of malaria. Population and Development Review 35:53-87. http://dx.doi.org/10.1111/ j.1728-4457.2009.00261.x

Pamuk, E. R., R. Fuchs, and W. Lutz. 2011. Comparing relative effects of education and economic resources on infant mortality in developing countries. Population and Development Review 37:637-664. http://dx.doi.org/10.1111/j.1728-4457.2011.00451.x

Pearson, K. 1900. On the criterion that a given system of deviations from the probable in the case of a correlated system of variables is such that it can be reasonably supposed to have arisen from random sampling. Philosophical Magazine 50:157-175. http://dx.doi.org/http://dx.doi.org/10.1080/14786440009463897

Peterson, I., L. N. Borrell, W. El-Sadr, and A. Teklehaimanot. 2009. Individual and household level factors associated with malaria incidence in a highland region of Ethiopia: a multilevel analysis. American Journal of Tropical Medicine and Hygiene 80:103-111.

Pindolia, D., A. Garcia, A. Wesolowski, D. Smith, C. Buckee, A. Noor, R. Snow, and A. Tatem. 2012. Human movement data for malaria control and elimination strategic planning. Malaria Journal 11:205. http://dx.doi.org/10.1186/1475-2875-11-205

R Core Team. 2013. R: a language and environment for statistical computing. R Foundation for Statistical Computing, Vienna, Austria.

Rashed, S., H. Johnson, P. Dongier, R. Moreau, C. Lee, J. Lambert, and C. Schaefer. 2000. Economic impact of febrile morbidity and use of permethrin-impregnated bed nets in a malarious area II. Determinants of febrile episodes and the cost of their treatment and malaria prevention. American Journal of Tropical Medicine and Hygiene 62:181-186.

Robert, V., K. Macintyre, J. Keating, J.-F. Trape, J.-B. Duchemin, M. Warren, and J. C. Beier. 2003. Malaria transmission in urban sub-Saharan Africa. American Journal of Tropical Medicine and Hygiene 68:169-176.

RStudio. 2013. RStudio-Home. [online] URL: http://www. rstudio.com/

Rutstein, S. O., and K. Johnson. 2004. Demographic and health survey wealth index. ORC Macro, MEASURE DHS, Calverton, Maryland, USA.

Rutstein, S. O., and G. Rojas. 2006. Guide to DHS statistics. ORC Macro, Calverton, Maryland, USA.

Sachs, J., and P. Malaney. 2002. The economic and social burden of malaria. Nature 415:680-685. http://dx.doi.org/10.1038/415680a

Safeukui-Noubissi, I., S. Ranque, B. Poudiougou, M. Keita, A. Traoré, D. Traoré, M. Diakité, M. B. Cissé, M. M. Keita, A. Dessein, and O. K. Doumbo. 2004. Risk factors for severe malaria in Bamako, Mali: a matched case-control study. Microbes and Infection 6:572-578. http://dx.doi.org/10.1016/j.micinf.2004.02.007

Schellenberg, J. A., C. G. Victora, A. Mushi, D. de Savigny, D. Schellenberg, H. Mshinda, and J. Bryce. 2003. Inequities among 
the very poor: health care for children in rural southern Tanzania. Lancet 361:561-566. http://dx.doi.org/10.1016/S0140-6736(03) $\underline{12515-9}$

Schwartz, L., G. V. Brown, B. Genton, and V. S. Moorthy. 2012. A review of malaria vaccine clinical projects based on the WHO rainbow table. Malaria Journal 11:11. http://dx.doi. org/10.1186/1475-2875-11-11

Siri, J. G., M. L. Wilson, S. Murray, D. H. Rosen, J. M. Vulule, L. Slutsker, and K. A. Lindblade. 2010. Significance of travel to rural areas as a risk factor for malarial anemia in an urban setting. American Journal of Tropical Medicine and Hygiene 82:391-397. http://dx.doi.org/10.4269/ajtmh.2010.09-0047

Snow, R. W., E. A. Okiro, P. W. Gething, R. Atun, and S. I. Hay. 2010. Equity and adequacy of international donor assistance for global malaria control: an analysis of populations at risk and external funding commitments. Lancet 376:1409-1416. http://dx. doi.org/10.1016/S0140-6736(10)61340-2

Somi, M. F., J. R. G. Butler, F. Vahid, J. Njau, S. P. Kachur, and S. Abdulla. 2007. Is there evidence for dual causation between malaria and socioeconomic status? Findings from rural Tanzania. American Journal of Tropical Medicine and Hygiene 77:10201027.

Tanner, M., and D. de Savigny. 2008. Malaria eradication back on the table. Bulletin of the World Health Organization 86:82. http://dx.doi.org/10.2471/BLT.07.050633

Tanzania Commission for AIDS, Zanzibar AIDS Commission, National Bureau of Statistics, Office of the Chief Government Statistician, and ICF International. 2013. Tanzania HIV/AIDS and malaria indicator survey 2011-12. Dar es Salaam, Tanzania.

Tatem, A. J., C. A. Guerra, C. W. Kabaria, A. M. Noor, and S. I. Hay. 2008. Human population, urban settlement patterns and their impact on Plasmodium falciparum malaria endemicity. Malaria Journal 7:218. http://dx.doi.org/10.1186/1475-2875-7-218

Teklehaimanot, A., and P. Mejia. 2008. Malaria and poverty. Annals of the New York Academy of Sciences 1136:32-37. http:// dx.doi.org/10.1196/annals.1425.037

Townson, H. 2009. SIT for African malaria vectors: epilogue. Malaria Journal 8:S10. http://dx.doi.org/10.1186/1475-2875-8$\underline{\mathrm{S} 2-\mathrm{S} 10}$

Uganda Bureau of Statistics and ICF Macro. 2010. Uganda malaria indicator survey 2009. Calverton, Maryland, USA.

Velleman, P. F., and R. E. Welsch. 1981. Efficient computing of regression diagnostics. American Statistician 35:234-242.

Villamor, E., M. R. Fataki, R. L. Mbise, and W. W. Fawzi. 2003. Malaria parasitaemia in relation to HIV status and vitamin A supplementation among pre-school children. Tropical Medicine \& International Health 8:1051-1061. http://dx.doi.org/10.1046/ j.1360-2276.2003.01134.x

Vitor-Silva, S., R. C. Reyes-Lecca, T. R. Pinheiro, and M. V. Lacerda. 2009. Malaria is associated with poor school performance in an endemic area of the Brazilian Amazon. Malaria Journal 8:230. http://dx.doi.org/10.1186/1475-2875-8-230
Vyas, S., and L. Kumaranayake. 2006. Constructing socioeconomic status indices: how to use principal components analysis. Health Policy and Planning 21:459-468. http://dx.doi. org/10.1093/heapol/czl029

World Health Organization (WHO). 2008. Global malaria control and elimination: report of a technical review. World Health Organization, Geneva, Switzerland.

World Health Organization (WHO). 2010. Guidelines for the treatment of malaria - 2nd edition. World Health Organization, Geneva, Switzerland.

World Health Organization (WHO). 2011. World malaria report 2011. World Health Organization, Geneva, Switzerland.

Worrall, E., S. Basu, and K. Hanson. 2005. Is malaria a disease of poverty? A review of the literature. Tropical Medicine \& International Health 10:1047-1059. http://dx.doi.org/10.1111/ j.1365-3156.2005.01476.x 


\section{Appendix 1. Asset-based wealth index}

For each country, we validated the principal components-based wealth index by examining the proportion of households in wealth quintile categories with the assets used to construct the index.

A1.1: Proportion of households with particular indicator assets, by wealth quintile category.

\begin{tabular}{|c|c|c|c|}
\hline \multirow{2}{*}{ Country/Variable } & \multicolumn{3}{|c|}{ Wealth Category } \\
\hline & $\begin{array}{c}\text { Quintiles I \& II } \\
\text { (poorest) }\end{array}$ & $\begin{array}{c}\text { Quintiles III \& } \\
\text { IV }\end{array}$ & $\begin{array}{l}\text { Quintile V } \\
\text { (wealthiest) }\end{array}$ \\
\hline \multicolumn{4}{|l|}{ Angola } \\
\hline \multicolumn{4}{|l|}{ Asset ownership (proportion) } \\
\hline Car & 0.0000 & 0.0336 & 0.4594 \\
\hline Motorcycle & 0.0828 & 0.2041 & 0.1623 \\
\hline Bicycle & 0.1431 & 0.1154 & 0.1710 \\
\hline Refrigerator & 0.0000 & 0.0629 & 0.7478 \\
\hline TV & 0.0086 & 0.5487 & 0.9793 \\
\hline Radio & 0.2224 & 0.8002 & 0.9499 \\
\hline Mobile phone & 0.0474 & 0.7020 & 1.0000 \\
\hline \multicolumn{4}{|c|}{ Access to utilities/infrastructure (proportion) } \\
\hline Electricity & 0.0069 & 0.2989 & 0.9568 \\
\hline Improved drinking water source & 0.1397 & 0.6555 & 0.8100 \\
\hline Flush toilet & 0.0129 & 0.2127 & 0.6269 \\
\hline \multicolumn{4}{|l|}{ Characteristics of living residence } \\
\hline Number of dwelling rooms (mean) & 1.560 & 1.930 & 2.287 \\
\hline Floor of finished materials & 0.0052 & 0.4057 & 0.9793 \\
\hline \multicolumn{4}{|l|}{ Liberia } \\
\hline \multicolumn{4}{|l|}{ Asset ownership (proportion) } \\
\hline Car & 0.0000 & 0.0000 & 0.0813 \\
\hline Motorcycle & 0.0000 & 0.0229 & 0.2262 \\
\hline Bicycle & 0.0000 & 0.0033 & 0.1012 \\
\hline Refrigerator & 0.0000 & 0.0054 & 0.0747 \\
\hline TV & 0.0000 & 0.0011 & 0.2544 \\
\hline Radio & 0.1841 & 0.5854 & 0.8239 \\
\hline Mobile phone & 0.0299 & 0.6746 & 0.9235 \\
\hline \multicolumn{4}{|c|}{ Access to utilities/infrastructure (proportion) } \\
\hline Electricity & 0.0000 & 0.0033 & 0.1096 \\
\hline Improved drinking water source & 0.5313 & 0.7854 & 0.8809 \\
\hline Flush toilet & 0.0040 & 0.0621 & 0.3855 \\
\hline \multicolumn{4}{|l|}{ Characteristics of living residence } \\
\hline Number of dwelling rooms (mean) & 1.508 & 1.937 & 2.622 \\
\hline Floor of finished materials & 0.1045 & 0.4477 & 0.8434 \\
\hline \multicolumn{4}{|l|}{ Uganda } \\
\hline \multicolumn{4}{|l|}{ Asset ownership (proportion) } \\
\hline Car & 0.0000 & 0.0000 & 0.0637 \\
\hline Motorcycle & 0.0000 & 0.0235 & 0.2695 \\
\hline Bicycle & 0.2329 & 0.6843 & 0.5309 \\
\hline Refrigerator & 0.0029 & 0.0103 & 0.1244 \\
\hline TV & 0.0000 & 0.0037 & 0.3230 \\
\hline Radio & 0.3857 & 0.8389 & 0.9146 \\
\hline Mobile phone & 0.0323 & 0.6505 & 0.9246 \\
\hline
\end{tabular}


Access to utilities/infrastructure (proportion)

Electricity

0.0000

0.0118

0.3204

Improved drinking water source

0.6231

0.7670

0.8822

Flush toilet

0.0000

0.0000

0.0442

Characteristics of living residence

Number of dwelling rooms (mean)

1.648

2.076

2.298

Floor of finished materials

0.0022

0.1112

0.8483

Malawi

Asset ownership (proportion)

Car

Motorcycle

0.0000

0.0000

0.0712

Bicycle

0.0000

0.0039

0.0501

Refrigerator

0.3607

0.4862

0.4512

TV

0.0000

0.0026

0.2375

Radio

0.0000

0.0052

0.6280

0.1777

0.6579

0.9499

Mobile phone

0.0265

0.5793

0.9551

Access to utilities/infrastructure (proportion)

Electricity

Improved drinking water source

0.0000

0.0013

0.4670

Flush toilet

0.6379

0.8689

0.9551

0.0000

0.0000

0.0897

Characteristics of living residence

Number of dwelling rooms (mean)

$\begin{array}{lll}1.512 & 1.965 & 2.285\end{array}$

Floor of finished materials

0.0027

0.1887

0.8865

\begin{tabular}{l}
\hline Rwanda \\
\hline Asset ownership (proportion) \\
Car \\
Motorcycle \\
Bicycle \\
Refrigerator \\
TV \\
Radio \\
Mobile phone \\
Access to utilities/infrastructure (proportion) \\
Electricity \\
Improved drinking water source \\
Flush toilet \\
Characteristics of living residence \\
Number of dwelling rooms (mean) \\
Floor of finished materials \\
\hline Senegal \\
Asset ownership (proportion) \\
Car \\
Motorcycle \\
Bicycle \\
Refrigerator \\
TV \\
Radio \\
Mobile phone \\
Access to utilities/infrastructure (proportion) \\
Electricity \\
Improved drinking water source \\
Flush toilet
\end{tabular}

Flush toilet

0.0000

0.0000

0.0366

0.0000

0.0000

0.2469

0.0379

0.0000

0.5342

0.0000

1.850

0.0000

0.0105

0.0056

0.1252

0.0000

0.0168

0.6273

0.4916

0.0189

0.5734

0.0637
0.0000

0.0000

0.1779

0.0000

0.0027

0.8383

0.5490

0.0067

0.8094

0.0000

2.285

0.0646

0.0161

0.0862

0.2726

0.0147

0.4688

0.9222

0.9636

0.0343

0.0395

0.4690

0.0514

0.2537

0.9447

0.9407

0.4214

0.9037

0.0396

2.591

0.6192

0.0610

0.2741

0.2177

0.6175

0.8862

0.9753

0.9648

0.8872

0.4569

0.9110

0.7389
0.6629

0.4386 


\begin{tabular}{|c|c|c|c|}
\hline $\begin{array}{l}\text { Characteristics of living residence } \\
\text { Number of dwelling rooms (mean) } \\
\text { Floor of finished materials }\end{array}$ & $\begin{array}{c}3.879 \\
0.1400\end{array}$ & $\begin{array}{c}5.418 \\
0.5902\end{array}$ & $\begin{array}{c}6.503 \\
0.7925\end{array}$ \\
\hline \multicolumn{4}{|l|}{ Tanzania } \\
\hline \multicolumn{4}{|l|}{ Asset ownership (proportion) } \\
\hline Car & 0.0008 & 0.0034 & 0.0673 \\
\hline Motorcycle & 0.0034 & 0.0566 & 0.2343 \\
\hline Bicycle & 0.4295 & 0.7341 & 0.6053 \\
\hline Refrigerator & 0.0000 & 0.0008 & 0.2308 \\
\hline TV & 0.0041 & 0.0189 & 0.5058 \\
\hline Radio & 0.3363 & 0.7998 & 0.8516 \\
\hline Mobile phone & 0.2089 & 0.9086 & 0.9764 \\
\hline \multicolumn{4}{|c|}{ Access to utilities/infrastructure (proportion) } \\
\hline Electricity & 0.0000 & 0.0057 & 0.4966 \\
\hline Improved drinking water source & 0.3202 & 0.5634 & 0.8423 \\
\hline Flush toilet & 0.0004 & 0.0095 & 0.3432 \\
\hline \multicolumn{4}{|l|}{ Characteristics of living residence } \\
\hline Number of dwelling rooms (mean) & 2.225 & 2.897 & 2.980 \\
\hline Floor of finished materials & 0.0038 & 0.1988 & 0.9026 \\
\hline \multicolumn{4}{|l|}{ Nigeria } \\
\hline \multicolumn{4}{|l|}{ Asset ownership (proportion) } \\
\hline Car & 0.0069 & 0.0533 & 0.3345 \\
\hline Motorcycle & 0.2291 & 0.5223 & 0.5398 \\
\hline Bicycle & 0.2781 & 0.2915 & 0.2632 \\
\hline Refrigerator & 0.0006 & 0.0584 & 0.6318 \\
\hline TV & 0.0259 & 0.5338 & 0.9648 \\
\hline Radio & 0.4496 & 0.8562 & 0.9578 \\
\hline Mobile phone & 0.1929 & 0.8797 & 0.9813 \\
\hline \multicolumn{4}{|c|}{ Access to utilities/infrastructure (proportion) } \\
\hline Electricity & 0.1382 & 0.5790 & 0.9237 \\
\hline Improved drinking water source & 0.3788 & 0.5848 & 0.7115 \\
\hline Flush toilet & 0.0178 & 0.0968 & 0.4322 \\
\hline \multicolumn{4}{|l|}{ Characteristics of living residence } \\
\hline Number of dwelling rooms (mean) & 2.421 & 2.970 & 3.157 \\
\hline Floor of finished materials & 0.2596 & 0.7225 & 0.9295 \\
\hline \multicolumn{4}{|l|}{ Madagascar } \\
\hline \multicolumn{4}{|l|}{ Asset ownership (proportion) } \\
\hline Car & 0.0000 & 0.0015 & 0.0646 \\
\hline Motorcycle & 0.0000 & 0.0010 & 0.1159 \\
\hline Bicycle & 0.0468 & 0.2347 & 0.4767 \\
\hline Refrigerator & 0.0000 & 0.0000 & 0.1216 \\
\hline TV & 0.0000 & 0.0059 & 0.6125 \\
\hline Radio & 0.2330 & 0.5296 & 0.8661 \\
\hline Mobile phone & 0.0000 & 0.1545 & 0.8367 \\
\hline \multicolumn{4}{|c|}{ Access to utilities/infrastructure (proportion) } \\
\hline Electricity & 0.0000 & 0.0142 & 0.6762 \\
\hline Improved drinking water source & 0.0000 & 0.5516 & 0.8063 \\
\hline Flush toilet & 0.0000 & 0.0132 & 0.1491 \\
\hline \multicolumn{4}{|l|}{ Characteristics of living residence } \\
\hline Number of dwelling rooms (mean) & 1.182 & 1.504 & 1.980 \\
\hline Floor of finished materials & 0.0000 & 0.1555 & 0.7626 \\
\hline
\end{tabular}

